\title{
What Do Majority-Voting Politics Say About Redistributive Taxation of Consumption AND Factor Income? Not Much.
}

\author{
JIM DoLmas \\ Research Department \\ Working Paper 0814
}




\title{
What do majority-voting politics say about redistributive taxation of consumption and factor income? Not much.
}

\author{
Jim Dolmas* \\ Federal Reserve Bank of Dallas
}

\begin{abstract}
Tax rates on labor income, capital income and consumption - and the redistributive transfers those taxes finance - differ widely across developed countries. Can majority-voting methods, applied to a calibrated growth model, explain that variation? The answer I find is yes, and then some. In this paper, I examine a simple growth model, calibrated roughly to US data, in which the political decision is over constant paths of taxes on factor income and consumption, used to finance a lump-sum transfer. I first look at outcomes under probabilistic voting, and find that equilibria are extremely sensitive to the specification of uncertainty. I then consider other ways to restrict the range of majority-rule outcomes, looking at the model's implications for the shape of the Pareto set and the uncovered set, and the existence or non-existence of a Condorcet winner. Solving the model on discrete grid of policy choices, I find that no Condorcet winner exists and that the Pareto and uncovered sets, while small relative to the entire issue space, are large relative to the range of tax policies we see in data for a collection of 20 OECD countries. Taking that data as the issue space, I find that none of the 20 can be ruled out on efficiency grounds, and that 10 of the 20 are in the uncovered set. Those 10 encompass policies as diverse as those of the US, Norway and Austria. One can construct a Condorcet cycle including all 10 countries' tax vectors.

The key features of the model here, as compared to other models on the endogenous determination of taxes and redistribution, is that the issue space is multidimensional and, at the same time, no one voter type is sufficiently numerous to be decisive. I conclude that the sharp predictions of papers in this literature may not survive an expansion of their issue spaces or the allowance for a slightly less homogeneous electorate.
\end{abstract}

JEL classification: D72, D78, E62, H23

${ }^{*}$ Research Department, Federal Reserve Bank of Dallas, 2200 North Pearl Street, Dallas, TX 75201. e-mail: jim.dolmas@dal.frb.org. The views expressed in this paper are those of the author and do not necessarily reflect the views of the Federal Reserve Bank of Dallas nor of the Federal Reserve System. I thank Erwan Quintin, Evan Koenig and Sheila Dolmas for many helpful comments. Any errors are my own. 
Keywords: Political economy, redistribution, voting, probabilistic voting, uncovered set This version: July 2008

\section{Introduction and motivation}

This paper was originally motivated by a claim, made in Peter Lindert's book Growing Public: Social Spending and Economic Growth Since the Eighteenth Century, that European welfare states, which redistribute a much larger share of income than, say, the United States, suffer few, if any, of the adverse consequences on the size of national output that economists might expect, because the tax systems they use to finance this redistribution are more efficient-in particular, by relying more heavily on the taxation of consumption, and less heavily on the taxation of income. The Economist of April 1, 2004, summarized the argument, in an article discussing Lindert's book:

The big European and Nordic welfare states are undoubtedly expensive. But their economic costs are held down by the perhaps surprisingly efficient tax systems with which they are financed. Once the means of finance are taken into account, they are also less redistributive than you might expect.

Economic theory has a lot to say about efficient systems of taxation. One guiding principle is that it is better to tax consumption than income, because taxing what is spent rather than what is earned does less damage to incentives to save. If wages are taxed, and the interest on savings is taxed also, then anything saved out of your wages is, in effect, taxed twice. Compared with the Americans, the Europeans place far more of their tax burden on consumption than income.

Indeed, rates of taxation on consumption, labor income and capital income vary markedly across developed countries. Table 1 reports estimates of average effective tax rates for a sample of OECD countries, over the period 1990-2000, taken from Carey and Rabesona [4]. The countries in Table 1 are ordered by their tax rates on consumption, in increasing order. One could look at tax rates for other periods or the estimates of other authors-Mendoza, Tesar and Razin [19], for example - but the wide variety of observed policies would remain a feature of the data.

Given the variety of tax policies we see in Table 1, the sort of question I had in mind was something like the following: Can we write down a fairly simple growth model which, when coupled with a majority-voting mechanism that endogenously determines consumption and income taxes, can rationalize the wide variety of tax policies we observe in terms of the exogenous structure of the model economy - as a consequence of differences in technology, for example, or differences in the initial distributions of wealth or earnings ability? One might also wonder - given that one of the available policy instruments is a consumption tax - whether a reasonable model could deliver a positive rate of capital income taxation as a politico-economic equilibrium. Why, in fact, do we see taxes on income at all, given the availability of taxes on consumption, and the economist's 


\begin{tabular}{|l|c|c|c|}
\hline & Consumption & Labor income & Capital income \\
\hline United States & 6.4 & 23.4 & 27.3 \\
\hline Japan & 6.4 & 24.1 & 27.9 \\
\hline Switzerland & 9.3 & 30.9 & 27.1 \\
\hline Australia & 12.1 & 20.9 & 30.7 \\
\hline Germany & 13.4 & 35 & 21.2 \\
\hline Canada & 13.9 & 29.6 & 36.8 \\
\hline Italy & 13.9 & 37.7 & 31 \\
\hline Spain & 14.5 & 30.7 & 20 \\
\hline Belgium & 15 & 41.3 & 32.7 \\
\hline France & 15.1 & 40.5 & 33.2 \\
\hline Greece & 15.5 & 34.9 & 12.9 \\
\hline United Kingdom & 15.7 & 22.6 & 34 \\
\hline Korea & 15.8 & 9.9 & 16.7 \\
\hline Austria & 16.2 & 39.6 & 24.3 \\
\hline Netherlands & 18 & 36.4 & 32.7 \\
\hline Finland & 18.7 & 45 & 26 \\
\hline Sweden & 19.8 & 49.6 & 35.7 \\
\hline Portugal & 19.9 & 23.9 & 17.6 \\
\hline Denmark & 20.6 & 39.9 & 39.5 \\
\hline Norway & 25.7 & 36.2 & 24.7 \\
\hline Mean & $\mathbf{1 5 . 3}$ & $\mathbf{3 2 . 6}$ & $\mathbf{2 7 . 6}$ \\
\hline Standard deviation & $\mathbf{4 . 6}$ & $\mathbf{9 . 6}$ & $\mathbf{7 . 2}$ \\
\hline Standard deviation, percent of mean & $\mathbf{3 0 . 4}$ & $\mathbf{2 9 . 4}$ & $\mathbf{2 6 . 2}$ \\
\hline
\end{tabular}

Table 1: Average effective tax rates in a sample of OECD countries, 1990-2000, percent (Source: Carey and Rabesona, 2002) 
'guiding principle' that taxes on consumption are preferable, on efficiency grounds, to taxes on income?

It's important for this sort of analysis that the taxes used to finance redistribution are distortionary. Voting over how to divide a dollar, a pie or any fixed quantity of resources almost necessarily leads to a lack of majority-rule equilibria, at least in pure strategies - any candidate division of the pie can be defeated by an alternative division that shifts resources away from one voter and towards the others. With distortionary taxes, however, the size of the pie is linked to the manner in which it is allocated. If the distortionary effects of taxation are sufficiently strong, there is some hope that the tools of majority voting, applied to a model economy, can pin down a unique equilibrium outcome or, barring that, may at least result in a narrow range of 'plausible' outcomes. That consideration is, in fact, one justification for choosing the model which I will elaborate below, the other main consideration being its simplicity. The model is not the standard neoclassical growth model, but rather a two-sector $A K$ model - a model in which the capital-producing technology is linear, and in which taxes, in particular capital income taxes, have potentially severe consequences for the size of the economic pie. I would conjecture that if majority voting methods fail to pin down a narrow set of plausible outcomes in this model, the results would only be less conclusive in a more standard model.

The model I work with in this paper is simpler in some respects than many models in the literature on endogenous taxation and redistribution - for example, the political decisions I consider assume full commitment at date zero to constant paths of taxes - but it is more complicated in one important respect: the issue space is multi-dimensional, consisting of taxes on capital income, labor income and consumption, and, at the same time, the electorate is calibrated in such a way that no single type of household constitutes a majority. Papers in this literature, which I survey briefly below, typically achieve determinant political equilibria by assuming either that the issue space consists of a single tax parameter or that one group of voters is decisive in each election.

An issue space with three dimensions seems to be the minimal size for explaining Table 1. And, even if one is primarily interested in explaining only cross-country differences in the size of redistributive transfers - the size of the welfare state - Lindert's claim suggests that the size of transfers and the composition of financing are inextricably linked. Can one have a good theory of cross-country differences in the size of transfers without explaining differences in tax systems? The assumption that no household type is assumed decisive, on the other hand, is a modeling choice, with which one might disagree. However, given that three of the last five U.S. presidential winners have been elected with less than $50 \%$ of the popular vote - and that, outside of the U.S., strong third-parties seem to be the rule rather than the exception - exploring whether determinant outcomes are readily obtained with a less-homogeneous electorate seems a worthwhile exercise.

With policies to be described by three tax rates - and the level of redistributive transfers being determined by a government budget constraint, as will be described below-it seemed clear at 
the outset that the mechanism for generating political outcomes in the model would have to be something other than simple Downsian two-party competition over tax policy platforms. Verifying the conditions of the median voter theorem is a difficult task in settings where the issue space is multi-dimensional. In the context of the model I will elaborate below - a model that, while simple in many respects, is sufficiently complicated that analytic expressions for individual policy preferences cannot be obtained - verifying something like Plott's [22] condition, for example, would be impossible. My initial inclination, then, was to apply probabilistic voting, which seemed wellsuited to models with multidimensional issue spaces. ${ }^{1}$

To preview the main results, discussed in greater detail below, outcomes under probabilistic voting proved fragile. In fact, for a loose calibration of the model, depending on whether the (logistically distributed) random terms in agents' preferences were additive or multiplicative, the equilibrium tax vectors were not merely different, but in fact orthogonal. For a more careful calibration - the specific parameter values are given in section 3 - the outcomes under additive or multiplicative random elements were no longer orthogonal, but nearly so. While one equilibrium relied heavily on consumption and capital income taxes, the other had a zero consumption tax rate and a very light capital income tax rate. While one had a $33 \%$ tax rate on labor income, the other had a zero tax rate on labor income. While one resulted in transfers equal to $63 \%$ of GDP, the other had transfers that were essentially zero.

Given the disparity in outcomes under the two specifications of probabilistic voting, it seemed natural to ask whether one or the other outcome was more appropriate according to more theoretically grounded criteria - for example, are one or both outcomes (or perhaps neither) in the Pareto set, the set of alternatives that are not Pareto-dominated by other alternatives? While the model described below treats the issue space as a subset of $R^{3}$, for practical purposes the model can only be solved computationally on a discrete, finite grid of tax vectors. Given a finite grid on which the model is solved, does there exist a Condorcet winner - that is, an alternative which wins all pairwise contests? Barring that, what does the model's uncovered set look like? ${ }^{2}$ What I find, for a particular parametrization of the model, solved on a discrete grid of tax vectors, is that: no Condorcet winner exists, and while the Pareto and uncovered sets are small relative to the entire issue space, they are both large relative to the range of observed outcomes summarized in Table 1. That is, most of the alternatives in Table 1 are within, or very close to, both the Pareto set and uncovered set.

\footnotetext{
${ }^{1}$ Probabilistic voting is described in section 4.3 .

${ }^{2}$ The uncovered set is defined more precisely below. It is a subset of the Pareto set and contains the Condorcet winner, if one exists. In two-candidate, majority-rule elections, a candidate ought to be reluctant to espouse a platform outside the uncovered set-such platforms represent dominated strategies. In settings where a decision is made amongst a finite set of alternatives using an amendment procedure (alternative 1 faces alternative 2 , the winner faces 3 , the winner of that faces 4 , etc., until all alternatives are exhausted) the set of sophisticated voting outcomes lies in the uncovered set. See Miller [20], Ordeshook [21] or Banks [1].
} 
Given the results of simulating the model, I turn specifically to the data in Table 1. One interpretation of the previous results is that without further structure on the political process, beyond a basic assumption of majority voting, our model economy is as likely to adopt a tax policy that looks like that of the U.S. as it is that of a European welfare state. As further confirmation of this interpretation, I take the data from Table 1 as comprising the model's issue space, and calculate the model's Pareto set and uncovered set given that restricted list of alternatives. The Pareto set is the entire list of 20 alternatives. Of the 20 alternatives, 10 are in the uncovered set, including countries like the U.S. and Japan, but also Austria and Norway. The uncovered set is not reducible ${ }^{3}$, and, perhaps not surprisingly, given McKelvey [17], one can construct a Condorcet cycle including all 10 uncovered alternatives.

The remainder of the paper is organized as follows. The next section describes the model economy - the choice problems faced by firms and households, the government's budget constraint and the economy's resource constraints - and characterizes balanced growth equilibria for a given, constant set of taxes on capital income, labor income and consumption. Since the model can only be solved computationally, I spend some time in section 3 describing the calibration of the model's parameters. In section 4, I present the model's implication for political outcomes - equilibria under probabilistic voting, the model's Pareto set and the uncovered set. I also discuss the model's predictions when the issue space is taken to be the 20 tax vectors given in Table 1 . I offer some concluding comments in section 5. Some of the derivations in the construction of balanced growth equilibria and model calibration, as well as other analytical details, are relegated to an appendix, which appears at the end of the paper. First, though, I briefly survey some of the literature to which the paper is related.

\subsection{Related literature}

This paper is related to several papers in the growing literature on the endogenous determination of taxes and redistribution in dynamic economic models. Many of these models examine environments that are richer, along some dimensions, than the environment I consider in this paper. These models typically feature limited commitment to future tax rates, so political decisions must be taken at regular intervals. In some, the economy's distribution of wealth holdings can evolve in complex ways, and the authors must exercise great care in tracking that evolution and its impact on political outcomes. Most of the papers in this literature are simpler, though, in two important respects - either the political decision is one-dimensional (a single income tax rate that determines a transfer payment via the government's budget constraint) or there is one household type in the economy whose share in the population is greater than or equal to one half (so that majority preferences are simply the preferences of that household type). The results in this paper are not

\footnotetext{
${ }^{3}$ Reducibility, discussed further below, would allow us narrow down the location of sophisticated voting outcomes to a proper subset of the uncovered set.
} 
intended to diminish the work of these authors - the problems they tackle are difficult enough on their own terms - but simply to suggest that the sharp predictions for political equilibria that they obtain might not survive an expansion of the set of available tax instruments or an allowance for a less homogeneous electorate.

Krusell and Rios-Rull [13] extend Meltzer and Richard's [18] static theory of the size of government to the dynamic setting of the neoclassical growth model with heterogeneous agents. In their model there is a single flat-rate tax on income used to finance a lump-sum transfer. The government follows a balanced budget, so a choice of tax rate implies a transfer payment, yielding an issue space which is one-dimensional. Taxes are decided on every two periods, and are constant between political decisions. The authors focus on Markov equilibria, with the distribution of capital and the current tax rate as state variables. There are three types of agents and, with a one-dimensional issue space, Krusell and Rios-Rull are able to verify computationally that agents' preferences over the tax rate are single-peaked. They are thus able to apply the median voter theorem in a relatively straightforward way. Krusell and Rios-Rull take great care in calibrating their model to match facts on the U.S. distributions of income and wealth. They find that the total size of transfers predicted by the model is close to what we see in the data.

Krusell, Quadrini and Rios-Rull [12] extend the analytical and computational framework of Krusell and Rios-Rull [13] to compare consumption tax systems and income tax systems under majority voting. They study economies with only a consumption tax, only an income tax and with both taxes together. While the latter case expands the issue space beyond one dimension, the authors assume a population structure in which one household type is decisive - political outcomes thus maximize the utility of that household type. Among other results, they find that systems that rely on taxing income may yield higher steady state welfare compared to systems that rely on taxing consumption. The additional distortions that come from taxing income act to reduce the steady state size of government transfers in their model. When both types of taxes are allowed, their median household chooses a positive consumption tax rate and a negative income tax rate; they conclude that the consumption tax is being used to raise revenue while the income tax is being used to mitigate some of the distortion associated with the consumption tax. In the model I present below, I constrain all tax rates to be non-negative; allowing for possibly negative tax rates on capital or labor income may be an interesting extension.

Hassler, Rodriguez Mora, Storesletten and Zilibotti [9] present a model with repeated voting over redistributive taxation. The model features an overlapping generations structure in which agents are identical in their first period of life, but have either high or low income in their second period of life, depending on their draw of a random productivity variable. Investments made by agents when young can increase the probability of their becoming successful when old. The issue space in the model is one-dimensional - the political decision is the size of a lump-sum redistribution, which implies a lump-sum tax. The tax is paid by all agents, but the benefit is 
received only by those who get the low-income draw. The electorate consists of the current old, which are divided between high-income and low-income individuals. The fraction of low-income old is a key state variable in their model, since it determines whether the decisive voter is a low-income or high-income old agent. Since this fraction depends on investment undertaken when agents were young, and the incentive to undertake investment is less the greater the level of redistribution, Hassler et al.'s model features a self-reinforcing feedback from current redistributive policies to future demand for redistribution. Their model has multiple equilibria, and makes a number of interesting predictions regarding the persistence and potential fragility of the welfare state.

Hassler, Krusell, Storesletten and Zilibotti [10] extend Hassler et al. [9] to a model with a richer set of agent types which features two layers of uncertainty - upon birth, agents are subject to an ability shock which assigns a fraction of the cohort to be 'workers' (who have the lowest income) and the rest 'entrepreneurs'; 'entrepreneurs' then undertake a costly investment which influences the probability of their being 'successful' or 'unsuccessful' in the second period of their lives. Agents have preferences such that they are ex ante risk averse, but ex post risk neutral. Ex ante risk aversion gives a rationale for positive transfers over and above any purely redistributive concerns. As in [9], the model features a feedback from redistribution to effort choice, hence to the distribution of 'success', and thus to the demand for redistribution. Among other results, the authors find that politically-determined redistribution in their model is larger and more persistent than would be chosen by a social planner under commitment. This is a model with a complex electorate. In the authors' benchmark case, next period's taxes are decided by the currently young, but after both types of uncertainty have been resolved - so the electorate consists of agents who will enter the subsequent period as either workers, unsuccessful entrepreneurs or successful entrepreneurs. The authors also consider a case where both young and old are permitted to vote over current benefits. In order to facilitate the determination of unique political equilibria, the authors adopt a form of probabilistic voting that results in an equilibrium benefit choice that, in effect, maximizes a utilitarian social welfare function for the electorate. ${ }^{4}$

Lastly, in the literature on social choice, DeDonder [7] performs calculations similar in spirit to those which I undertake in section 4.4. DeDonder considers a static model of redistribution in which agents have quadratic utility functions over consumption, work effort and capital supplied to the economy's productive sector (which produces consumption using capital and labor as inputs to a linear technology). The government taxes consumption and capital income at flat rates and rebates the proceeds to agents as a lump-sum transfer. For given tax rates, equilibrium in this economy leads to indirect utilities for agents which are quadratic in the two tax rates. The profiles

\footnotetext{
${ }^{4}$ See their equation (5), which describes what they term the political aggregation of individual preferences. The authors are not explicit about the assumptions underlying this equation, but it seems that the random, nonpolicy elements in agents' preferences must enter additively and be uniformly distributed. Other distributional assumptions - including one of the ones I consider below - also have the implication that voting outcomes maximize a utilitarian social welfare function. See below, section 4.3 , footnote 15 .
} 
of preferences over tax rates that thus emerge describe a type of two-dimensional spatial model, where each agent type has an ideal tax policy, and an agent's utility falls as the implemented policy is further from his or her ideal. Assuming that the two variables that describe each agent's ideal tax rates are bivariately log-normal, DeDonder simulates the model and calculates the average size of the model's uncovered set - as well as other majority-voting solution sets-across many simulations. DeDonder finds that his solution sets are small relative to the entire issue space, and thus concludes that they yield sharp predictions for the outcomes of the redistributive voting game he considers. My approach here differs from DeDonder's in that the model I consider is a fully-articulated dynamic general equilibrium growth model, which I attempt to calibrate in a way that is at least plausible. My focus, too, is less on the size of sets like the uncovered set relative to the entire issue space, but rather relative to the variation we see in the cross-country data. Like DeDonder, I find that the uncovered set is a small fraction of the entire issue space-here, about $7 \%$-but its shape is still such that it rules out very little in terms of the range of policies summarized in Table 1.

\section{The model economy}

The economy is populated by a large number of infinitely-lived households, with the size of the population normalized to one. Time is discrete and there is no uncertainty. Households are distinguished by their initial endowments of capital and the productivity of the hours of labor they supply. The economy's production sector consists of technologies for producing consumption and new capital. The government levies flat rate taxes on households' income from labor and capital and on consumption, and redistributes the proceeds - net of revenue needed to finance exogenous government consumption - as a lump-sum transfer.

Characterizing the decision problem facing households is easier if we have in hand some of the equilibrium price relationships implied by zero-profit conditions in the production sector. Thus, I will describe the production side of the economy before turning to household behavior. The government's behavior, which is rather simple, is described last.

\subsection{Production sector}

The production side of the economy is a two-sector $A K$ structure in the spirit of Rebelo [23]. One sector produces a consumption good $(Z)$ using a Cobb-Douglas technology with capital and effective labor as inputs. The other sector produces new capital $(X)$ using an $A K$ technology with existing capital $(K)$ as the only input. Letting upper-case letters represent aggregate quantities, the technologies are

$$
Z_{t}=\left(\eta_{t} K_{t}\right)^{\alpha} N_{t}^{1-\alpha}
$$

and

$$
X_{t}=A\left(1-\eta_{t}\right) K_{t} .
$$


Here, $\eta_{t}$ denotes the fraction of the aggregate capital stock, $K_{t}$, devoted to the production of the consumption good, $Z_{t}$, and $1-\eta_{t}$ the fraction of the capital stock devoted to the production of new capital. Output of the consumption good, $Z_{t}$, will ultimately be divided between private consumption $C_{t}$ and government consumption $G_{t}$. The determination of $G_{t}$, which is exogenous and does not enter households' utility functions, will be described in more detail below. $N_{t}$ is the aggregate quantity of effective labor employed; the distinction between hours worked and effective labor will become clearer when we consider the problem facing households in the economy. $A$ is a scale parameter that determines the productivity of investment in new capital.

Under constant returns to scale, the number of firms is indeterminate, so assume for simplicity that a single price-taking firm operates the production sector. The firm rents capital and effective labor from households at prices $r_{t}$ and $w_{t}$, and chooses $N_{t}, K_{t}$ and $\eta_{t}$ to solve

$$
\max Z_{t}+q_{t} X_{t}-w_{t} N_{t}-r_{t} K_{t}
$$

subject to the production technologies given in (1) and (2). Here, $q_{t}$ is the price of new capital in units of the consumption good. With constant returns to scale, the firm must earn zero profit in equilibrium.

The first-order conditions for the firm's problem can be written as

$$
\begin{gathered}
(1-\alpha) \frac{Z_{t}}{N_{t}}=w_{t} \\
\eta_{t}\left(\alpha \frac{Z_{t}}{\eta_{t} K_{t}}\right)+\left(1-\eta_{t}\right) q_{t} A=r_{t}
\end{gathered}
$$

and

$$
\alpha \frac{Z_{t}}{\eta_{t} K_{t}}=q_{t} A
$$

The last two conditions, taken together, require that $r_{t}$ and $q_{t}$ be such that

$$
r_{t}=q_{t} A=\alpha \frac{Z_{t}}{\eta_{t} K_{t}}
$$

if profits are to be zero in equilibrium. We will exploit this feature of equilibrium below.

Note that national income, which I will denote by $Y_{t}$, obeys

$$
\begin{aligned}
Y_{t} & =w_{t} N_{t}+r_{t} K_{t} \\
& =(1-\alpha) Z_{t}+\left(\alpha / \eta_{t}\right) Z_{t} \\
& =\left(1-\alpha+\frac{\alpha}{\eta_{t}}\right) Z_{t} .
\end{aligned}
$$


Note also that when $N_{t}$ and $\eta_{t}$ are constant (as will be the case in the balanced growth equilibria I consider), then the growth rates of the consumption good, capital and the price of capital goods are related by

$$
\frac{Z_{t+1}}{Z_{t}}=\left(\frac{K_{t+1}}{K_{t}}\right)^{\alpha}
$$

- from (1) - and

$$
\frac{q_{t+1}}{q_{t}}=\frac{Z_{t+1} / K_{t+1}}{Z_{t} / K_{t}}=\frac{Z_{t+1} / Z_{t}}{K_{t+1} / K_{t}}=\left(\frac{K_{t+1}}{K_{t}}\right)^{\alpha-1}
$$

- from (3) and (5).

\subsection{Households}

The model features a continuum of households and a finite number of household types. Each period, households rent labor and capital to the economy's production sector, using the resulting income (net of taxes and transfers) to purchase consumption and new units of capital. A household that chooses to work $n_{t}$ hours in period $t$ supplies $e n_{t}$ units of effective labor, where $e$ is a productivity parameter that differs across groups of households, but is constant over time. Initial endowments of capital also vary across groups of households. I normalize the economy's initial aggregate stock of capital $K_{0}$ to be one, and let the variable $s$ denote households' shares of the initial stock, so a 'type- $(e, s)$ ' household begins with an initial endowment of capital equal to $s$. Note that in a balanced growth equilibrium with constant tax rates, the capital stock of a type$(e, s)$ household always obeys $k_{t} / K_{t}=s-i . e .$, the relative distribution of capital is unchanging over time.

The population size is normalized to unity. Let $p(e, s)$ denotes the mass of households of type $(e, s)$; then, $\sum_{(e, s) \in \mathfrak{T}} p(e, s)=1$ where $\mathfrak{T}$ is the (finite) set of household types.

Each household pays three types of taxes - capital and labor income taxes and a consumption tax - and receives a lump-sum transfer payment. A typical household faces a sequence of budget constraints of the form

$$
\left(1-\tau_{k}\right) r_{t} k_{t}+\left(1-\tau_{n}\right) w_{t} e n_{t}+T_{t}=\left(1+\tau_{c}\right) c_{t}+q_{t} x_{t}
$$

where $\tau_{k}$ and $\tau_{n}$ are the income tax rates, $\tau_{c}$ is the consumption tax rate, and $T_{t}$ is the transfer payment; $w_{t}$ and $r_{t}$ are the wage and rental rates, respectively; and $q_{t}$ is the price of new capital in units of consumption. I've omitted time subscripts on the tax rates, since these will be constant under the political equilibria I consider-I assume full commitment to constant tax rates from date zero on. Capital depreciates at rate $\delta$, so a household's holding of capital evolves according to

$$
k_{t+1}=(1-\delta) k_{t}+x_{t}
$$


The household's preferences feature a constant elasticity of intertemporal substitution. I find it convenient to work with a transformation of preferences that is degree-one homogeneous in consumption. Lifetime utility is given by

$$
u_{0}=\left[(1-\beta) \sum_{t=0}^{\infty} \beta^{t}\left(c_{t}\left(1-n_{t}\right)^{\psi}\right)^{1-(1 / \varepsilon)}\right]^{\frac{1}{1-(1 / \varepsilon)}}
$$

where $\varepsilon>0$ is the elasticity of intertemporal substitution, and the parameter $\psi$ governs the trade-off between consumption and leisure (one minus hours worked).

A typical household's decision problem can be thought of in terms of its intratemporal and intertemporal aspects. In any period, given prices, the transfer payment, the household's capital at the start of the period and its planned purchase of capital for next period, the intratemporal problem can be written in terms of consumption and leisure as

$$
\max _{c, l} c l^{\psi}
$$

subject to

$$
\left(1-\tau_{k}\right) r_{t} k_{t}+\left(1-\tau_{n}\right) w_{t} e+T_{t}-q_{t}\left[k_{t+1}-(1-\delta) k_{t}\right]=\left(1+\tau_{c}\right) c+\left(1-\tau_{n}\right) w_{t} e l
$$

and

$$
1 \geq l \geq 0
$$

Note that the intratemporal choice problem is restricted to those values $k_{t}, k_{t+1}$, etc., such that $\left(1-\tau_{k}\right) r_{t} k_{t}+\left(1-\tau_{n}\right) w_{t} e+T_{t}-q_{t}\left[k_{t+1}-(1-\delta) k_{t}\right]>0$.

In a representative agent economy - given the Inada conditions present in both preferences and technology - the inequality constraints $0 \leq l \leq 1$ would not be binding in equilibrium. With heterogeneous households, however - and given that the households receive a lump-sum transfer and own capital - we must allow for the possibility that some households will choose to supply zero hours of work to the production sector - i.e., that the $l \leq 1$ constraint might bind. For example, households with relatively low values of the productivity parameter $e$ and high values of $s$ may choose not to supply labor in some equilibria.

It's straightforward to show that when the $l \leq 1$ constraint does not bind, the household 'spends' constant shares of its full income (the left-hand side of (10)) on consumption and leisure. Letting $c_{t}$ and $l_{t}$ denote the solutions to the problem at $t$, we have

$$
\left(1+\tau_{c}\right) c_{t}=\frac{1}{1+\psi}\left\{\left(1-\tau_{k}\right) r_{t} k_{t}+\left(1-\tau_{n}\right) w_{t} e+T_{t}-q_{t}\left[k_{t+1}-(1-\delta) k_{t}\right]\right\}
$$


and

$$
\left(1-\tau_{n}\right) w_{t} e l_{t}=\frac{\psi}{1+\psi}\left\{\left(1-\tau_{k}\right) r_{t} k_{t}+\left(1-\tau_{n}\right) w_{t} e+T_{t}-q_{t}\left[k_{t+1}-(1-\delta) k_{t}\right]\right\} .
$$

The second of these, together with $n_{t}=1-l_{t}$, gives the household's supply of effective labor effort when the $l \leq 1$ constraint is slack:

$$
e n_{t}=\frac{1}{1+\psi} e-\frac{\psi}{1+\psi} \frac{\left(1-\tau_{k}\right) r_{t} k_{t}+T_{t}-q_{t}\left[k_{t+1}-(1-\delta) k_{t}\right]}{\left(1-\tau_{n}\right) w_{t}} .
$$

When the $l \leq 1$ constraint binds, the household has

$$
l_{t}=1
$$

(or $\left.e n_{t}=0\right)$ and

$$
\left(1+\tau_{c}\right) c_{t}=\left(1-\tau_{k}\right) r_{t} k_{t}+T_{t}-q_{t}\left[k_{t+1}-(1-\delta) k_{t}\right] .
$$

The constraint will bind precisely when the right-hand side of (12) is non-positive. Note that while the consumption tax rate $\tau_{c}$ has no direct impact on either the intensive or extensive margins of household labor supply (in the intratemporal problem), it will exercise an indirect influence through the transfer $T_{t}$. Other things the same, a higher value of $T_{t}$ reduces the supply of effective labor effort.

One can show - as we'll see below - that in a balanced growth equilibrium, whether a household supplies a positive amount of labor effort depends on its value of $e$ and its capital holdings relative to the aggregate capital stock, $s=k_{t} / K_{t}$, both of which are constant in equilibrium (the former by assumption, the latter as a feature of a balanced growth path). Consequently, a household that supplies zero labor in a period always supplies zero labor, while a household that supplies a positive amount of labor always supplies a positive amount of labor. Thus, to characterize the solution to the household's intertemporal problem, it's enough to consider Euler equations assuming the household is either always constrained or always unconstrained.

In either case - unconstrained or constrained - the household's Euler equations take the form

$$
\left(c_{t}\right)^{-1 / \varepsilon}\left(l_{t}\right)^{\psi(1-1 / \varepsilon)}=\beta\left(c_{t+1}\right)^{-1 / \varepsilon}\left(l_{t+1}\right)^{\psi(1-1 / \varepsilon)} \frac{\left(1-\tau_{k}\right) r_{t+1}+(1-\delta) q_{t+1}}{q_{t}} .
$$

Anticipating the arguments of section 2.4, suppose that $q_{t+1} / q_{t}$ is constant and equal to $1+g_{q}$. Using $r_{t}=q_{t} A$, the return to investment in physical capital on the right-hand side of the Euler equation is constant and given by

$$
\frac{\left(1-\tau_{k}\right) r_{t+1}+(1-\delta) q_{t+1}}{q_{t}}=\left(1+g_{q}\right)\left[\left(1-\tau_{k}\right) A+1-\delta\right]
$$


If leisure is constant - as will be the case under balanced growth - the growth rate of household consumption obeys

$$
1+g_{c}=\left(\beta\left(1+g_{q}\right)\left(\left(1-\tau_{k}\right) A+1-\delta\right)\right)^{\varepsilon} .
$$

If the transfer payment $T_{t}$ and the real wage $w_{t}$ also grow at the constant rate $1+g_{c}$, it's clear that a path for household capital that grows at a constant rate and, in particular, is such that $q_{t} k_{t}$ also grows at rate $1+g_{c}$, will satisfy the household's Euler equations.

In standard fashion, restrictions on the models parameters, and restrictions on admissible values of $\tau_{k}$-restrictions guaranteeing that $\beta\left(1+g_{c}\right)^{1-(1 / \varepsilon)}<1$-will guarantee that the paths just described satisfy households' transversality conditions as well. A more detailed discussion of the solution to the household's problem, and the construction of a balanced growth path, is contained in the appendix.

\subsection{Government}

The government in this model simply levies taxes and redistributes the revenue - in excess of an amount needed to finance government consumption - as a lump-sum transfer to households. Tax rates and the transfer are non-targeted - that is, they are identical across households. I assume that the government runs a balanced budget in each period. The government's budget constraint is:

$$
\tau_{k} r_{t} K_{t}+\tau_{n} w_{t} N_{t}+\tau_{c} C_{t}=T_{t}+G_{t}
$$

where $G_{t}$ is exogenously specified government consumption. Recall that we have a measure one of households. Therefore, aggregate and average quantities coincide, so that $T_{t}$ is both aggregate transfer spending and the per-household transfer payment.

To keep consistency with balanced growth under alternative tax policies, government consumption $G_{t}$ is assumed to be specified as a constant fraction of the economy's output of the consumption good $Z_{t}$ :

$$
G_{t}=\lambda Z_{t}
$$

Redistributive policy is then determined by choices of the tax rates $\tau_{k}, \tau_{n}$ and $\tau_{c}$, with $T_{t}$ residually determined from the budget constraint. In the numerical simulations of the model that I perform below, I impose the restriction that $T_{t} \geq 0$-i.e., I do not allow lump-sum financing of $G_{t}$. I impose this constraint for the sake of realism: we almost never see governments finance their consumption through lump-sum taxes. At the same time, it's difficult to write down a model where lump-sum taxes would not be chosen if they were available, so they are ruled out by assumption.

How the tax rates $\tau_{k}, \tau_{n}$ and $\tau_{c}$ are set - which will determine the size of the transfer - will be described in a subsequent section.

Remark 1 At this point, one may ask, Why this particular model? The model has a couple 
virtues. First, as discussed in the introduction, the distortionary effects of taxes, especially capital income taxes, are more severe here than in the standard neoclassical growth model. I would conjecture that the further we move away from the case of pure redistribution of a fixed stock of resources, majority-voting methods are more likely to be conclusive. Obviously, the simplicity of the model is also appealing, in particular its lack of transitional dynamics. Also, because the economy will immediately be on a balanced growth path, the assumption of constant tax rates becomes less restrictive, though not entirely innocuous. Since the relative standings of households in the economy's wealth and earnings distributions do not change, their preferences over constant tax rates do not change. If the political decision is a set of tax rates for now and into the indefinite future, revisiting that decision at a later date would lead to the same outcome.

Remark 2 Setting aside the particular problem at hand, is the AK framework a good model of economic growth? The evidence on this is mixed. Models of this sort imply a link between rates of investment and rates of growth, which Jones [8], for example, concludes are not present in the data. McGrattan [16] offers a critique of Jones's findings and concludes that the investment-growth connection predicted by AK models is consistent with the data.

\subsection{Balanced growth equilibria with constant tax rates}

This section describes the economy's balanced growth equilibrium for given values of the tax parameters.

Given constant tax rates and an initial distribution of capital holdings, an equilibrium consists of sequences of prices $\left\{w_{t}, r_{t}, q_{t}\right\}_{t=0}^{\infty}$; production decisions $\left\{K_{t}, N_{t}, \eta_{t}\right\}_{t=0}^{\infty}$; a set of household decisions for each household type $(e, s)$, denoted $\left\{c_{t}(e, s), n_{t}(e, s), k_{t+1}(e, s)\right\}_{t=0}^{\infty}$; and a sequence of transfer payments $\left\{T_{t}\right\}_{t=0}^{\infty}$ such that: (a) the household decisions for each household type maximize that type's lifetime utility; (b) the production decisions maximize profits (at zero) in the production sector; (c) the government's budget constraint is satisfied at each date; and (d) the allocations are feasible - i.e., the following resource constraints are satisfied at every date:

$$
\begin{gathered}
\sum_{(e, s) \in \mathfrak{T}} p(e, s) c_{t}(e, s)=C_{t}=Z_{t}-G_{t}=(1-\lambda) B\left(\eta_{t} K_{t}\right)^{\alpha} N_{t}^{1-\alpha} \\
\sum_{(e, s) \in \mathfrak{T}} p(e, s)\left[k_{t+1}(e, s)-(1-\delta) k_{t}(e, s)\right]=X_{t}=A\left(1-\eta_{t}\right) K_{t} \\
\sum_{(e, s) \in \mathfrak{T}} p(e, s) e n_{t}(e, s)=N_{t} \\
\sum_{(e, s) \in \mathfrak{T}} p(e, s) k_{t}(e, s)=K_{t} .
\end{gathered}
$$

Note that the resource constraints for gross investment and the capital stock imply that aggregate 
capital grows according to

$$
\frac{K_{t+1}}{K_{t}}=A\left(1-\eta_{t}\right)+1-\delta
$$

A balanced growth equilibrium is an equilibrium in which (a) consumption, capital stocks, prices and transfer payments grow at constant rates, and (b) $\eta_{t}$ and the $n_{t}(e, s)$ 's are constant. The construction of balanced growth equilibria is described in detail in the appendix; in this section I simply characterize such equilibria.

As described in section 2.1, equation (5), the structure of the production sector dictates that in a balanced growth equilibrium output of the consumption good-hence also household consumption and the transfer payment - will grow at a rate $g_{Z}$, while capital stocks will grow at a rate $g_{K}$, with

$$
1+g_{Z}=\left(1+g_{K}\right)^{\alpha}
$$

To be consistent with households' budget constraints (or efficiency conditions in the production sector), $w_{t}$ must share the same growth rate as consumption, while $q_{t}$ and $r_{t}$ share a common growth rate $g_{q}$ satisfying $\left(1+g_{q}\right)\left(1+g_{K}\right)=1+g_{Z}$. With $1+g_{Z}=\left(1+g_{K}\right)^{\alpha}$, we have

$$
1+g_{q}=\frac{1+g_{Z}}{1+g_{K}}=\left(1+g_{K}\right)^{\alpha-1} .
$$

The keys to calculating a balanced growth equilibrium are the determination of $\eta$ (which pins down $g_{K}$ ) and the household labor supply decisions $n(e, s)$ (which pin down $N$ and, together with $\eta$, everything else).

To see the determination of $\eta$, consider the Euler equations for a typical household, assuming that $l_{t}$ is constant, that $q_{t+1} / q_{t}=1+g_{q}$, and using $r_{t+1}=q_{t+1} A$ :

$$
\frac{c_{t+1}}{c_{t}}=\left(\beta\left(1+g_{q}\right)\left[\left(1-\tau_{k}\right) A+1-\delta\right]\right)^{\varepsilon} .
$$

In a balanced growth equilibrium, aggregate private consumption's share of $Z_{t}$ is constant, as are households' shares of aggregate private consumption, so the left-hand side of the last expression equals $1+g_{Z}$. Using (17) and (18), we can replace $1+g_{Z}$ and $1+g_{q}$ with $1+g_{K}$ and rearrange to get:

$$
1+g_{K}=\left(\beta\left[\left(1-\tau_{k}\right) A+1-\delta\right]\right)^{\frac{\varepsilon}{\alpha+\varepsilon(1-\alpha)}} .
$$

Since $1+g_{K}=A(1-\eta)+1-\delta$, this determines $\eta^{*}$ as

$$
\eta^{*}=1-\frac{\left(\beta\left[\left(1-\tau_{k}\right) A+1-\delta\right]\right)^{\frac{\varepsilon}{\alpha+\varepsilon(1-\alpha)}}-(1-\delta)}{A} .
$$

Note that the capital growth rate depends only on the capital income tax rate $\tau_{k}$, and not on 
the labor income or consumption tax rates. Note too that the determination of $\eta^{*}$ doesn't rely on a particular choice of aggregate effective labor effort, $N$, only the assumption that $N$ is constant. Thus, we can determine the equilibrium value of $N$ taking $\eta^{*}$ as given.

The determination of household (and aggregate) labor supply is complicated by the fact that some households may choose to supply zero hours in some equilibria. ${ }^{5}$ In the appendix, I show that in a balanced growth equilibrium, the supply of effective labor by an unconstrained household of type $(e, s)$ will be:

$$
\frac{1}{1+\psi} e-\frac{\psi}{1+\psi}\left\{\frac{\eta^{*}-\tau_{k}}{(1-\alpha)\left(1-\tau_{n}\right)} \frac{\alpha}{\eta^{*}} s+\frac{\tau_{k} \alpha / \eta^{*}+\tau_{n}(1-\alpha)+\tau_{c}(1-\lambda)-\lambda}{\left(1-\tau_{n}\right)(1-\alpha)}\right\} N,
$$

More generally, for any household type $(e, s)$, effective labor supply in a balanced growth equilibrium is given by the maximum of the last expression and zero.

Let $\Phi(e, s ; N, \tau)$ denote the last expression (20), where $\tau$ denotes the vector of tax rates $\tau=\left(\tau_{c}, \tau_{n}, \tau_{k}\right)$. Note that if $\Phi(e, s ; N, \tau)>0$ then so is $\Phi\left(e^{\prime}, s^{\prime} ; N, \tau\right)$ if either $e^{\prime} \geq e$ or $s^{\prime} \leq s$; that is, if household type $(e, s)$ works in equilibrium, so will any household which has either higher labor productivity or a smaller endowment of capital. Equilibrium aggregate effective labordenote it $N^{*}$-is then given implicitly by the following equation in $N$ :

$$
N=\sum_{(e, s) \in \mathfrak{T}} p(e, s) \max \{\Phi(e, s ; N, \tau), 0\}
$$

Given $N^{*}$ and $\eta^{*}$-and the economy's initial capital stock $K_{0}=1$-the paths of all aggregate quantities and prices are determined. Capital at any date is $K_{t}^{*}=\left[A\left(1-\eta^{*}\right)+1-\delta\right]^{t} K_{0}$ and output of the consumption good is $Z_{t}^{*}=B\left(\eta^{*} K_{t}^{*}\right)^{\alpha}\left(N^{*}\right)^{1-a}$. Equilibrium prices are given by plugging the equilibrium aggregates into the appropriate expressions from section 2.1. Each household's stock of capital grows at the same rate as the aggregate stock, while the household's consumption and leisure choices follow from their decision rules-(11), (12), (14) and (15) - taking into account equilibrium prices, transfers and the path of household capital-i.e., that $k_{t+1}=\left(1+g_{K}\right) k_{t}$.

\section{Calibration}

While the model is a simple one in many respects - in particular, the $A K$ structure frees us from dealing with transitional dynamics - it is nonetheless sufficiently complicated that solving the model can only be done computationally. To do so, we need to specify values for the model's parameters.

I calibrate the model, roughly, to U.S. data. One could conceivably calibrate the model to data from another country among, say, those listed in Table 1, or to an average of some set of

\footnotetext{
${ }^{5}$ The aggregate labor input, because the consumption-producing technology obeys an Inada condition, will always be positive.
} 


\begin{tabular}{|l|l|}
\hline Quantity & Target \\
\hline Private consumption share of output & $65 \%$ \\
Government consumption $(G)$ share of output & $20 \%$ \\
Labor's share of national income & $60 \%$ \\
Fraction of time endowment spent working & $30 \%$ \\
Consumption growth rate & $2 \%$ per year \\
\hline
\end{tabular}

Table 2: Targets for calibration of parameters

countries. I choose the U.S. mainly because of the familiarity of the basic parameters, though I don't think the main conclusion of the paper - the qualitative conclusion, that majority voting imposes little discipline on the range of tax policies possible in politico-economic equilibrium - is sensitive to this decision. The numerical values of the tax policies obtained under probabilistic voting, or contained in the model's uncovered set, would differ for a different calibration, but the general inconclusiveness of the results will still obtain. Put differently, it's sufficient for my point, I think, that an economy calibrated to be in some respects 'like the U.S.' cannot decide whether it wants taxes that look like those of the U.S. or those of Norway. In any case, one should interpret the results as applying to a model economy calibrated to match certain stylized facts about the U.S. economy.

I calibrate the economy as if it were in a balanced growth equilibrium with taxes given by the U.S. data in Table 1: $\bar{\tau}=\left(\bar{\tau}_{c}, \bar{\tau}_{n}, \bar{\tau}_{k}\right)=(.064, .234, .273)$. I specify certain parameters without reference to the model's equilibrium behavior - in particular, I set $\varepsilon$, the elasticity of intertemporal substitution, to be 0.5 , and $\delta$, the capital depreciation rate, to be $10 \%$ per year. The value for $\varepsilon$ is within the range of most estimates, while the value for $\delta$ is a standard one used in calibrated growth models. The model's remaining taste and technology parameters - $\alpha, A, \psi, \lambda$ and $\beta$-are then calibrated to yield a balanced growth equilibrium that has the properties summarized in Table 2.

Calibration here is somewhat more complicated than in the more-familiar one-sector neoclassical growth model. In the neoclassical growth model, for example, $1-\alpha$ would represent labor's share of national income. In the present model, labor's share of national income and consumption's share of output are intertwined, and both are related to the equilibrium value of $\eta$, the fraction of capital devoted to producing the consumption good. The steps in calibrating the model - which I describe in detail in the appendix - are roughly as follows. The target values for the output shares of private and government consumption pin down $\lambda$, which is government's share of output of the consumption good. The target consumption shares plus the labor income share pin down a value of the parameter $\alpha$ and a balanced growth equilibrium value of $\eta$, call it $\bar{\eta}$. That $\bar{\eta}$, together with $\alpha$ and $\delta$, imply a unique value of $A$ that will meet the growth rate target in the last line of Table 2. The choice of $\beta$ is then such that, taken in conjunction with the other parameters and with $\bar{\tau}_{k}$, 
$\bar{\eta}$ is in fact chosen-i.e., the typical household's Euler equation is satisfied when the household's capital stock grows at rate $A(1-\bar{\eta})+1-\delta$. Finally, $\psi$ is chosen so that, given $\alpha, \lambda, \bar{\tau}_{c}$ and $\bar{\tau}_{n}$, the average household chooses to use $30 \%$ of its time endowment working. ${ }^{6}$

The other key parameters for which values need to be assigned are those describing the distribution of household types - that is, the possible values taken on by $(e, s)$ and their distribution $p(e, s) .{ }^{7}$ To keep the state space manageable, I assume that $e$ and $s$ each take on only two values, low or high. Taking account of combinations, this results in four household types$\mathfrak{T}=\left\{\left(e_{L}, s_{L}\right),\left(e_{L}, s_{H}\right),\left(e_{H}, s_{L}\right),\left(e_{H}, s_{H}\right)\right\}$. Both $e$ and $s$ are assumed to have a mean of 1 :

$$
\sum_{(e, s) \in \mathfrak{T}} p(e, s) e=\sum_{(e, s) \in \mathfrak{T}} p(e, s) s=1
$$

I assume the marginal distributions are such that

$$
\text { fraction of households with } e_{L}=\text { fraction of households with } s_{L}=\frac{6}{10}
$$

and

$$
\text { fraction of households with } e_{H}=\text { fraction of households with } s_{H}=\frac{4}{10} \text {. }
$$

The advantage of this latter assumption is that allows for a simple characterization of the correlation between $e$ and $s$. Let $p_{1}(e, s)$ be defined as

$$
p_{1}(e, s)=\left(\begin{array}{l}
p_{1}\left(e_{L}, s_{L}\right) p_{1}\left(e_{L}, s_{H}\right) \\
p_{1}\left(e_{H}, s_{L}\right) p_{1}\left(e_{H}, s_{H}\right)
\end{array}\right)=\left(\begin{array}{cc}
\frac{6}{10} & 0 \\
0 & \frac{4}{10}
\end{array}\right)
$$

and $p_{0}(e, s)$ defined as

$$
p_{0}(e, s)=\left(\begin{array}{cc}
\frac{36}{100} & \frac{24}{100} \\
\frac{24}{100} & \frac{16}{100}
\end{array}\right) .
$$

$p_{1}(e, s)$ would be the form of $p(e, s)$ assuming $e$ and $s$ were perfectly correlated, while $p_{0}(e, s)$ would be the form if $e$ and $s$ were uncorrelated. For any correlation in between, call it $\rho$, the implied $p(e, s)$ is given $\mathrm{by}^{8}$

$$
p(e, s)=\rho p_{1}(e, s)+(1-\rho) p_{0}(e, s) .
$$

\footnotetext{
${ }^{6}$ In fact, for this calculation I use the first-order conditions from the intratemporal problem that would obtain if there were a single representative household - equivalently, a household with consumption and work effort equal to aggregate consumption and work effort-since hours worked for such a household can be derived analytically. Because of convexity effects, average time spent working by households in the economy in a balanced growth equilibrium given taxes $\bar{\tau}$ will differ slightly from $30 \%$. Matching the average of household hours - rather than hours of an average household - would, however, entail solving a complicated fixed point problem in $\psi$.

${ }^{7}$ Given the simplified approach to calibrating $\psi$ described above, these distributional parameters played no role in the calibration of the parameters of tastes or technology.

${ }^{8}$ This uses the fact that both $e$ and $s$ have mean 1 .
} 
In the numerical experiments I perform, I set $\rho=.46$, which is the correlation between wealth and earnings in U.S. data reported by Budria Rodriguez, Diaz-Gimenez, Quadrini and Rios-Rull [3]. With this value of $\rho$, household $(e, s)$ types are distributed in the population according to

$$
p(e, s)=\left(\begin{array}{l}
.4704 .1296 \\
.1296 .2704
\end{array}\right)
$$

Note that the most numerous type - the $\left(e_{L}, s_{L}\right)$ households - amounts to just less than half the population, so no one household type will be decisive for the economy's political decisions.

The values of $e_{L}, e_{H}, s_{L}$ and $s_{H}$ are set in the following way. For the values of $s$, I use data on the quintiles of the U.S. distribution of wealth calculated in Budria Rodriguez et al [3]. In particular, I assume that the bottom $60 \%$ of the wealth distribution own $7 \%$ of the aggregate capital stock $\left(s_{L}=.07 / .60\right)$, while the top $40 \%$ own $93 \%\left(s_{H}=.93 / .40\right)$. For the values of $e$, I choose $e_{L}$ and $e_{H}$ to give a standard deviation of log wages across households equal to 0.55 , which is about in the middle of the numbers reported by Katz and Autor [11] for various years from 1963 to $1995 .^{9}$ This procedure implies $\left\{e_{L}, e_{H}\right\}=\{0.5467,1.6800\}$. Note that wealth in this economy is distributed much more unequally than earning ability; $s_{H} / s_{L} \cong 20$, while $e_{H} / e_{L} \cong 3$.

\section{Political equilibria}

\subsection{Household preferences over policies}

Any balanced growth equilibrium with constant tax rates gives rise to household preferences over the tax rates in the form of households' lifetime utilities from equilibrium consumption and leisure choices. Given the form of households' utility functions, if household consumption grows at the constant rate $g_{Z}$, and leisure hours are constant, a household's lifetime utility from date zero obeys

$$
u_{0}=\left(\frac{1-\beta}{1-\beta\left(1+g_{Z}\right)^{1-(1 / \varepsilon)}}\right)^{\frac{1}{1-(1 / \varepsilon)}} c_{0}\left(l_{0}\right)^{\psi}
$$

which is equally valid for $\varepsilon \neq 1$ or (in the limit) $\varepsilon=1$.

For this expression to make sense, we need $1>\beta\left(1+g_{Z}\right)^{1-\frac{1}{\varepsilon}}$, the equivalent here of the household's transversality condition. Recalling that $1+g_{Z}=\left(1+g_{K}\right)^{\alpha}=\left(\beta\left[\left(1-\tau_{k}\right) A+1-\delta\right]\right)^{\frac{\alpha \varepsilon}{\alpha+\varepsilon(1-\alpha)}}$, this requirement places restrictions on admissible values of the model parameters. The appendix discusses these restrictions in more detail.

Assuming $1>\beta\left(1+g_{Z}\right)^{1-\frac{1}{\varepsilon}}$ is satisfied, lifetime utility in a balanced growth equilibrium is given by (21), with $\left[A\left(1-\eta^{*}\right)+1-\delta\right]^{\alpha}$ for $1+g_{Z}$, and $c_{0}$ and $l_{0}$ given by the date-zero versions of either (11) and (12), or (14) and (15), with all prices set equal to their equilibrium values, $k_{1}$

\footnotetext{
${ }^{9}$ In Katz and Autor's data the standard deviation of log wages for all men and women rises from about 0.5 in 1963 to about 0.6 in 1995. See their Table 1.
} 
set equal to $\left[A\left(1-\eta^{*}\right)+1-\delta\right] s$, and $\eta^{*}$ as given in (19). The precise forms taken by $c_{0}$ and $l_{0}$ in equilibrium are given in the appendix.

For a household of type $(e, s)$, we let $V(\tau ; e, s)$ denote the lifetime utility function described above, with $\tau$ representing a particular vector of tax rates $\left(\tau_{c}, \tau_{n}, \tau_{k}\right)$.

\subsection{General assumptions on political equilibria}

Policy choices in the model are at date zero, through some form of majority voting. Under probabilistic voting, we imagine two-party competition in which candidates espouse tax platforms $\tau$, and households vote for one of the two candidates. The Pareto set and the uncovered set are relevant to two-party competition as well, as no candidate in such an election would want to espouse a platform outside of the Pareto set or the uncovered set. ${ }^{10}$ The uncovered set is also relevant to voting protocols where there is an agenda setter that faces households with an exhaustive sequence of pairwise contests to decide among a finite set of alternatives - say, an agenda for choosing amongst the alternatives in Table 1. In that case, it has been shown by Miller [20] that the set of sophisticated voting outcomes - roughly, the possible outcomes when voters take into account each other's optimal decisions and anticipate the effect that each round of voting has on the final outcome - lies in the uncovered set.

In any case, the decision taken at date zero is 'once and for all': the government commits to a constant path of tax rates. As discussed in Remark 1, this assumption, admittedly simplistic, is perhaps less stringent than meets the eye, when one considers the linear structure of the modelbecause household's relative wealth and earnings are constant over time, if voting were repeated at some future date (with alternatives again being tax rates for now and the indefinite future) the policy choice would be the same (assuming the political process identified a unique policy choice).

Exploring richer specifications, without commitment, is a topic for future research. Given the inconclusiveness that we obtain under the simplifying assumption of full commitment, however, it is unclear whether relaxing the assumption would prove a fruitful line of inquiry.

\subsection{Probabilistic voting}

Probabilistic voting has a long history as an alternative to deterministic voting models of the Downsian, median voter variety. Models where the issue space is multi-dimensional seem particularly well-suited to the probabilistic voting framework. The restrictions on preferences sufficient to yield the existence of a 'median voter' when the issue space is multi-dimensional are generally quite severe. ${ }^{11}$ As Ordeshook [21] writes, "Equilibrium is assured in deterministic models only if

\footnotetext{
${ }^{10}$ That no candidate would espouse a platform outside of the Pareto set is obvious, as such a platform could be unanimously defeated. The undesirability of platforms outside the uncovered set is discussed below in section 4.4.

${ }^{11}$ For example, in spatial voting models - where voters have ideal points in the issue space and a voter's utility declines with distance from the voter's ideal point-sufficient conditions have been given by Plott [22], Davis, DeGroot and Hinich [6], and others. Such sets of conditions typically require very special distributions of voters' ideal points, such that any line through the candidate majority-rule equilibrium divides the set of ideal points in
} 
we impose severe restrictions on the electorate's preference distribution, whereas the equilibrium just described [an example of probabilistic voting] can be shown to exist for far weaker assumptions about this distribution." An early application of probabilistic voting to the problem of redistribution is Lindbeck and Weibull [14]. Coughlin [5] is a standard theoretical reference. Yang [24] applies a logistic probabilistic voting framework, similar to that elaborated below, to the issue of tariff formation. Hassler, Krusell, Storesletten and Zilibotti [10] use a different, though related, form of probabilistic voting as the political equilibrium concept in their analysis of the dynamics of welfare states.

Suppose that two candidates, $a$ and $b$, espouse policies $\tau_{a}$ and $\tau_{b}$. Under deterministic voting, household $(e, s)$ would vote for $a$ over $b$ if and only if

$$
V\left(\tau_{a} ; e, s\right)>V\left(\tau_{b} ; e, s\right)
$$

Probabilistic voting, in its simplest form, adds a random element (from the candidates' point of view) to voters' preferences, which may represent non-policy considerations about the candidates that influence the utility voters get from having a particular candidate win office and implement his or her espoused platform. Suppose the random elements are additive, in particular that the utility household $(e, s)$ gets from a victory by candidate $a$ is given by

$$
V\left(\tau_{a} ; e, s\right)+\xi_{a}
$$

Then, $(e, s)$ would vote for $a$ over $b$ if and only if

$$
V\left(\tau_{a} ; e, s\right)+\xi_{a}>V\left(\tau_{b} ; e, s\right)+\xi_{b}
$$

The $\xi_{a}$ and $\xi_{b}$ here are assumed random from the candidates' points of view; households know their own preferences. Candidates are assumed to know the distribution of $\xi \equiv \xi_{a}-\xi_{b} .{ }^{12}$ Each candidate then knows that if $a$ espouses $\tau_{a}$ while $b$ espouses $\tau_{b}$, the probability that household $(e, s)$ will vote for $a$ over $b$ is

$$
\begin{aligned}
\operatorname{Pr}\{(e, s) \text { votes for } a \text { over } b\} & =\operatorname{Pr}\left\{\xi>V\left(\tau_{b} ; e, s\right)-V\left(\tau_{a} ; e, s\right)\right\} \\
& =1-F\left[V\left(\tau_{b} ; e, s\right)-V\left(\tau_{a} ; e, s\right)\right]
\end{aligned}
$$

where $F$ denotes the CDF of $\xi$.

Let $\pi_{a}\left(\tau_{a}, \tau_{b} ; e, s\right)$ denote the probability that $(e, s)$ votes for $a$ when the candidates' platforms half.

${ }^{12}$ The distribution of $\xi$ can be assumed to depend on $(e, s)$; more precisely, there may be a different distribution of $\xi$ for each household type. In what follows, though, I assume a logistic distribution for $\xi$, common across household types. 
are $\tau_{a}$ and $\tau_{b}$. Assume that $F(\cdot)$ has the logistic form, so $1-F(\omega)=\frac{1}{1+\exp (\omega)}$. Then,

$$
\pi_{a}\left(\tau_{a}, \tau_{b} ; e, s\right)=\frac{\exp \left[V\left(\tau_{a} ; e, s\right)\right]}{\exp \left[V\left(\tau_{a} ; e, s\right)\right]+\exp \left[V\left(\tau_{b} ; e, s\right)\right]}
$$

If, in contrast, the random non-policy elements enter household preferences multiplicatively, in the sense that

$$
(e, s) \text { 's utility from a victory by } a=\exp \left(\xi_{a}\right) V\left(\tau_{a} ; e, s\right) \text {, }
$$

then the probability that $(e, s)$ votes for $a$ is given by

$$
\pi_{a}\left(\tau_{a}, \tau_{b} ; e, s\right)=\frac{V\left(\tau_{a} ; e, s\right)}{V\left(\tau_{a} ; e, s\right)+V\left(\tau_{b} ; e, s\right)}
$$

Remark 3 As in Yang [24], I think of the random, non-policy elements in households' preferences as being normally distributed, and view the logistic distribution as a highly tractable approximation to normality. This choice is somewhat arbitrary. Note, too, that there is nothing in households' observable economic choices that would allow us to discriminate between a logistic or some other distribution or, for that matter, between multiplicative or additive disturbances. From the standpoint of households' economic decisions, different assumptions about the $\xi$ 's and their distribution simply amount to different monotone transformations of households' preferences.

The strategy set of each candidate is the set of $\tau$ vectors that are compatible with the existence of a balanced growth equilibrium with a nonnegative transfer payment. ${ }^{13}$ I also restrict the choices of $\tau$ to lie in $[0, .9] \times[0, .9] \times[0,1.4]$. Setting either $\tau_{k}$ or $\tau_{n}$ equal to one is problematic computationally, and while no natural upper bound exists for $\tau_{c}$, in practice the $\tau_{c} \leq 1.4$ constraint does not bind for the probabilistic voting equilibria that I calculate. ${ }^{14}$

The candidates' pay-off functions are assumed to be their expected pluralities (margins of victory). Candidate $a$ 's expected vote, with additive disturbances, is given by

$$
\sum_{(e, s) \in \mathfrak{T}} p(e, s) \pi_{a}\left(\tau_{a}, \tau_{b} ; e, s\right)=\sum_{(e, s) \in \mathfrak{T}} p(e, s)\left(\frac{\exp \left[V\left(\tau_{a} ; e, s\right)\right]}{\exp \left[V\left(\tau_{a} ; e, s\right)\right]+\exp \left[V\left(\tau_{b} ; e, s\right)\right]}\right)
$$

candidate $a$ 's expected plurality is then

$$
\sum_{(e, s) \in \mathfrak{T}} p(e, s)\left[\pi_{a}\left(\tau_{a}, \tau_{b} ; e, s\right)-\pi_{b}\left(\tau_{a}, \tau_{b} ; e, s\right)\right]=2 \sum_{(e, s) \in \mathfrak{T}} p(e, s)\left(\frac{\exp \left[V\left(\tau_{a} ; e, s\right)\right]}{\exp \left[V\left(\tau_{a} ; e, s\right)\right]+\exp \left[V\left(\tau_{b} ; e, s\right)\right]}\right)-1
$$

\footnotetext{
${ }^{13}$ A negative transfer payment would amount to lump-sum financing of $G$, which I rule out by assumption.

${ }^{14}$ And, $\tau_{c}=1.4$ is just above the largest consumption tax rate preferred by the four household types in the calculations reported below.
} 
An analogous expression, with $V(\cdot)$ replacing $\exp (V(\cdot))$, holds for the case of multiplicative disturbances. Symmetric expressions describe the expected plurality for candidate $b$. The two pay-off functions (and strategy sets) describe a two-person, zero-sum, normal-form game. I focus on symmetric pure-strategy equilibria of this game - $a$ chooses some $\tau_{a}^{*}, b$ chooses some $\tau_{b}^{*}$, the choices are best responses to one another, and $\tau_{a}^{*}=\tau_{b}^{*} \equiv \tau^{*}$.

Remark 4 Note that if utilities are differentiable in $\tau$, the first-order conditions for an interior maximum of (22) with respect to $\tau_{a}$, given $\tau_{b}$, evaluated at a symmetric equilibrium, take the form

$$
\sum_{(e, s) \in \mathfrak{T}} p(e, s) D_{\tau} V\left(\tau^{*} ; e, s\right)=0
$$

which are identical to the first-order conditions for maximizing a utilitarian social welfare function. If the first-order conditions have a unique solution - as would be the case under strict concavity, for example - then interior symmetric voting equilibria coincide with utilitarian social welfare maxima. This is also true in our case, even though the problem is posed on a discrete grid of tax vectors and corners do come into play - that is, the equilibrium $\tau_{\text {Additive }}^{*}$ described below is also the maximum of $\sum_{(e, s) \in \mathfrak{T}} p(e, s) V(\tau ; e, s)$. One can likewise show, for the case of multiplicative disturbances, that the first-order conditions describing a symmetric voting equilibrium are identical to the first-order conditions for maximizing $\sum_{(e, s) \in \mathfrak{T}} p(e, s) \ln [V(\tau ; e, s)] .{ }^{15}$

Given the complicated nature of the lifetime utility functions $V(\tau ; e, s)$, it would be surprising if one could give general conditions guaranteeing the existence of a symmetric equilibrium in this game, and I have not attempted to do so. Rather, I solve for a symmetric equilibrium of the game computationally, using the calibrated version of the model described in section 3 . For computational purposes, one must treat $\tau$ as taking on a finite set of values. I therefore approximate $[0, .9] \times[0, .9] \times[0,1.4]$ by having each of the two income taxes take on values only in the set $\{0, .01, .02, \ldots, .90\}$, while $\tau_{c}$ lies on the similarly spaced grid $\{0, .01, .02, \ldots, 1.4\}$.

The results of that exercise reveal the outcomes under probabilistic voting to be quite fragile with respect to the choice of additive or multiplicative disturbances. Under additive disturbances,

\footnotetext{
${ }^{15}$ Note that if the disturbances are additive but the distribution of $\xi$ is uniform on some interval $\left[\xi_{l}, \xi_{u}\right]$, then the probability that $(e, s)$ votes for $a, 1-F\left[V\left(\tau_{b} ; e, s\right)-V\left(\tau_{a} ; e, s\right)\right]$, is an increasing affine function of $V\left(\tau_{a} ; e, s\right)-$ $V\left(\tau_{b} ; e, s\right)$, so that $a$ 's expected plurality is an affine function of $\sum p(e, s) V\left(\tau_{a} ; e, s\right)$. In this case-which is similar to the form of probabilistic voting used in Hassler, Krusell, Storesletten and Zilibotti [10] — each candidate would choose the tax vector that maximizes utilitarian social welfare, regardless of the strategy employed by the candidate's opponent. If the disturbances are multiplicative, a candidate would seek to maximize $\sum p(e, s) \ln \left[V\left(\tau_{a} ; e, s\right)\right]$, analogous to the case of multiplicative disturbances under the logistic distribution which I use here.
} 
the symmetric equilibrium to the voting game described above turns out to be

$$
\tau_{\text {Additive }}^{*}=\left(\begin{array}{c}
0 \\
0.33 \\
0.10
\end{array}\right)
$$

- that is, a zero consumption tax; a labor income tax rate that is about average for the countries in Table 1; and a capital income tax that is rather light compared to what we see in the data. Assuming multiplicative disturbances, however, we obtain:

$$
\tau_{\text {Multiplicative }}^{*}=\left(\begin{array}{c}
1.06 \\
0 \\
0.25
\end{array}\right) .
$$

This equilibrium features a heavy reliance on the taxation of consumption; a capital income tax that is close to the average in Table 1; and no taxation of labor income..

Supposing that one were interested simply in the 'size of government' - that is, in the model's predictions for transfers as a percent of GDP - one might still wonder whether, in spite of the near-orthogonality of equilibrium tax policies, the equilibrium transfer rates were similar across the specifications of probabilistic voting. Unfortunately, this is not the case. $\tau_{\text {Additive }}^{*}$ corresponds, essentially, to zero redistribution, with $T_{t}$ approximately $0.008 \%$ of $Y_{t}$. That is, under additive disturbances, the probabilistic voting outcome simply finances exogenous government consumption, with virtually no redistribution. $\tau_{\mathrm{M} \text { ultiplicative, }}^{*}$ on the other hand, results in transfers equal to about $63 \%$ of GDP.

What's driving the difference between the outcomes under additive and multiplicative disturbances? It was noted in Remark 4 that for a model with differentiable, strictly concave household utilities, and assuming interior solutions, symmetric voting equilibria under additive and multiplicative disturbances correspond to solutions to the problems

$$
\max _{\tau} \sum_{(e, s) \in \mathfrak{T}} p(e, s) V(\tau ; e, s)
$$

and

$$
\max _{\tau} \sum_{(e, s) \in \mathfrak{T}} p(e, s) \ln [V(\tau ; e, s)],
$$

respectively. While the model here is solved on a discrete grid - and corner solutions do figure in the equilibria - this correspondence between symmetric probabilistic voting equilibria and the solutions to optimization problems turns out to still apply: $\tau_{\text {Additive }}^{*}$ does in fact solve (23) while $\tau_{\text {Multiplicative }}^{*}$ solves (24). The latter problem tends to put more weight, compared to the former, 
on the utilities of the poorer household types, and thus tends to move the solution closer to the preferred tax vectors of the poorer households. To see the intuition for this, note that under differentiability, $\tau_{\text {Multiplicative }}^{*}$ solves a problem analogous in form to the problem solved by $\tau_{\text {Additive }}^{*}$, but with different weights on the various household types, since $\tau_{\mathrm{Multiplicative}}^{*}$ would also solve

$$
\max \sum_{(e, s) \in \mathfrak{T}} \hat{p}(e, s) V(\tau ; e, s),
$$

where

$$
\hat{p}(e, s)=\frac{p(e, s) / V\left(\tau_{\text {Multiplicative }}^{*} ; e, s\right)}{\sum_{(e, s) \in \mathfrak{T}} p(e, s) / V\left(\tau_{\text {Multiplicative }}^{*} ; e, s\right)} .
$$

Given the greater disparity in household capital-holdings, compared to differences in labor productivity, the poorer households in the model economy - those that achieve lower levels of lifetime utility - are the two capital-poor household types. While $\tau_{\text {Multiplicative }}^{*}$ redistributes resources towards those household types, it does not completely erase the inequality in utility attainment, so that $\hat{p}(e, s)$ puts greater weight on the capital-poor household types as compared to $p(e, s)$. For the calibrated model used in the preceding calculations,

$$
\hat{p}(e, s)=\left(\begin{array}{l}
\hat{p}\left(e_{L}, s_{L}\right) \hat{p}\left(e_{L}, s_{H}\right) \\
\hat{p}\left(e_{H}, s_{L}\right) \hat{p}\left(e_{H}, s_{H}\right)
\end{array}\right)=\left(\begin{array}{l}
.6332 .0911 \\
.1111 .1646
\end{array}\right)
$$

while $p(e, s)$ continues to be given by

$$
p(e, s)=\left(\begin{array}{l}
.4704 .1296 \\
.1296 .2704
\end{array}\right) \text {. }
$$

As one might expect, given the difference between $\hat{p}(e, s)$ and $p(e, s), \tau_{\text {Multiplicative }}^{*}$ is closer to the preferred tax vectors of the two capital-poor household types than is $\tau_{\text {Additive }}^{*}$ on the grid of tax vectors used in this section, the households of type $\left(e_{H}, s_{H}\right)$ and $\left(e_{L}, s_{H}\right)$ both prefer $\tau=(0,0.50,0)$; households of type $\left(e_{H}, s_{L}\right)$ prefer $\tau=(0.09,0,0.43) ;$ and households of type $\left(e_{L}, s_{L}\right)$ prefer $\tau=(1.39,0.09,0.42) \cdot{ }^{16}$

For household preferences over consumption and leisure, the difference between additive or multiplicative disturbances amounts merely to a monotone transformation of lifetime utility. While innocuous from an economic standpoint, this transformation has a large impact on voting outcomes. Given that we know relatively little about the precise way that households' 'non-policy' preferences should enter into their lifetime utility functions, this fragility is problematic.

\footnotetext{
${ }^{16}$ These are the tax vectors which solve $\max V\left(\tau ; e_{i}, s_{j}\right)$. Note that the wealthiest household type, $\left(e_{H}, s_{H}\right)$, prefers positive taxes only because of the need to finance $G_{t}$. If we allowed $T_{t}<0$, the most preferred tax vector of type $\left(e_{H}, s_{H}\right)$ households would be $\tau=(0,0,0)$.
} 
The two equilibrium tax vectors above are nearly orthogonal. With an earlier version of the model - one that differed most importantly by assuming no government consumption and no correlation between wealth and productivity - the equilibrium outcomes were in fact orthogonal. In one case, only consumption and capital income taxes were used, while in the other only labor income taxes were used.

\subsection{The Pareto set and the uncovered set}

Given the two very different outcomes under the two specifications of probabilistic voting, it seemed a natural next step to ask whether one or the other was a more sensible equilibrium, relative to other solution concepts for majority-voting problems. If, for example, the model admitted a Condorcet winner on a coarse grid of tax vectors, is that point better approximated by one of the two probabilistic voting outcomes? If that were the case, then future experiments could be conducted using whichever of the two probabilistic voting specifications seemed to give the more sensible outcomes. ${ }^{17}$ It seemed a worthwhile strategy, then, to coarsen the set of alternatives down to a computationally manageable number, and use brute force methods to examine other solution concepts - to look, for example, at the size and structure of the Pareto set and the uncovered set, and, perhaps, to hunt for a Condorcet winner. This section summarizes the results of applying that approach to our model economy.

In this section, then, I drop the pretense that the grid of tax vectors is approximating a continuum, and suppose that the economy in fact faces a discrete set of choices. The Pareto set is the set of alternatives that are not unanimously defeated by other alternatives-i.e., the set of $\tau_{i}$ such that there does not exist $\tau_{j}$ with

$$
\sum_{\left\{e, s: V\left(\tau_{j} ; e, s\right)>V\left(\tau_{i} ; e, s\right)\right\}} p(e, s)=1
$$

Since points outside the Pareto set can be unanimously defeated, we would expect candidates under most any electoral rules to avoid them. Of course, in a purely redistributive setting, there's little information in the Pareto set - if voters are dividing a pie of fixed size, any allocation that uses up the entire pie will be in the Pareto set. Taxes in our model, however, are not purely redistributive - the consumption and labor income taxes distort household's intratemporal choices, and taxes on capital income can have severe adverse consequences for growth. There is at least some hope, then, that the Pareto set might be small relative to the entire issue space, and would thus restrict potential political outcomes in a meaningful way.

For calculating the Pareto set - and in fact for all the computations reported in this section-I

\footnotetext{
${ }^{17}$ Why not abandon probabilistic voting altogether at that point? A major advantage of probabilistic voting is that the equilibria can be calculated fairly quickly on a fine grid. The equilibria reported in the last section, for example, were calculated in a matter of minutes. By contrast, calculating the Pareto set and uncovered set on a much coarser grid - the results shown in Figures 1 and 2-took about 18 hours on a $1.8 \mathrm{GHz}$ Pentium laptop.
} 
take the set of alternatives to lie on a fairly coarse grid, with each of the two income tax rates taking on only 25 possible values, evenly spaced, between 0 and 0.90 , while the consumption tax rate takes on 38 possible values between 0 and 1.40 , for a total of 23,750 alternatives. The computations show that the effects of the taxes on the size of the economic 'pie' are in fact important - the Pareto set is only about $7 \%$ of the entire issue space. Nevertheless, its shape is such that our real-world data from Table 1 are, for the most part, either in it, or quite close to it.

Figure 1 plots the Pareto set in three-dimensional space, together with the data points from Table 1. Note that the data from Table 1 are simply super-imposed in the figure to give a sense of the variety of outcomes encompassed by the Pareto set; given the regularly-spaced grid of points used in the computations, none of the tax vectors from Table 1 actually reside in the issue space. Still, of the 20 tax schemes in the table, only 2-which are the high-capital-tax systems of Denmark and Sweden - seem definitely out of bounds.

Figure 1 suggests that, while ruling out Pareto inefficient alternatives narrows considerably the range of possible political outcomes, the alternatives that remain still vary widely, at least relative to real-world outcomes. The uncovered set, a subset of the Pareto set, potentially restricts outcomes further. Let $P$ denote the majority preference relation: $\tau_{i} P \tau_{j}$ if and only if

$$
\sum_{\left\{e, s: V\left(\tau_{i} ; e, s\right)>V\left(\tau_{j} ; e, s\right)\right\}} p(e, s)>\frac{1}{2}
$$

-in words, alternative $\tau_{i}$ is majority-preferred to $\tau_{j}$ if and only if the measure of households preferring $\tau_{i}$ to $\tau_{j}$ exceeds one half. Say that alternative $\tau_{j}$ covers $\tau_{i}$ if and only if $\tau_{j} P \tau_{i}$ and, if $\tau_{h} P \tau_{j}$, then $\tau_{h} P \tau_{i}$ as well. The uncovered set is the set of alternatives $\tau_{i}$ for which there exist no such $\tau_{j}$ covering them. When the majority preference relation is complete so that $\sim\left(\tau_{j} P \tau_{i}\right)$ is equivalent to $\tau_{i} P \tau_{j}$-we have the following alternative definition of covering: $\tau_{j}$ covers $\tau_{i}$ if and only if $\tau_{j} P \tau_{i}$ and $\tau_{i} P \tau_{h}$ implies $\tau_{j} P \tau_{h}$. That is, $\tau_{j}$ beats $\tau_{i}$ and beats any other alternative that $\tau_{i}$ beats. In that case, we can characterize the uncovered set as follows: $\tau_{i}$ is in the uncovered set if and only $\tau_{i}$ beats all other alternatives, either directly or at once remove. ${ }^{18}$ As discussed in Ordeshook [21], it's reasonable to suppose that candidates in an election will not choose platforms outside the uncovered set. To do so, when the majority preference relation is complete, would be to choose a dominated strategy: if a candidate espouses platform $\tau$, which is covered by some $\tau^{\prime}$, then switching to the covering platform $\tau^{\prime}$ would guarantee the candidate payoffs at least as large as $\tau$, and in some cases strictly larger, regardless of the strategy adopted by the candidate's opponent. ${ }^{19}$

Though less appropriate to the case of as many alternatives as shown in Figure 1-and more

\footnotetext{
${ }^{18}$ That is, for any $\tau_{j}$ either $\tau_{i} P \tau_{j}$ or there is a $\tau_{h}$ with $\tau_{i} P \tau_{h}$ and $\tau_{h} P \tau_{j}$.

${ }^{19}$ This assumes candidates care only about winning, losing or tying, with the payoff from winning strictly higher than the payoff from tying, which is strictly higher than the payoff from losing.
} 
appropriate to the experiments below in section 4.5-Miller [20] shows that under an amendment procedure, the set of sophisticated voting outcomes is a subset of the uncovered set. ${ }^{20} \mathrm{~A}$ recent empirical application of the uncovered set is Bianco, Jeliazkov and Sened [2], who use data on the policy preferences of U.S. House of Representatives members - along two dimensions, a civil rights dimension and an economic dimension - to estimate the size and location of the uncovered set for several Congressional sessions. They conclude that the uncovered set has substantial power for predicting policy outcomes in the sessions of Congress they examine.

So, what does the model's uncovered set look like? Unfortunately, it looks very much like the Pareto set, as can be seen in Figure 2. ${ }^{21}$ While a small fraction of the entire issue spaceapproximately $7 \%$ - the uncovered set is nonetheless large relative to the variety of tax policies we observe in the data.

The uncovered set is of a sufficiently small size that looking within it for a Condorcet winneran alternative which wins all pairwise contests - is computationally quick. I find that no Condorcet winner exists. Of the 1,727 elements in the uncovered set, the alternative which wins the most pairwise contests is $\left(\tau_{c}, \tau_{n}, \tau_{k}\right)=(0.6432,0,0.30)$, which defeats 1,446 other alternatives.

As with the results under probabilistic voting, one might wonder whether the transfer rates associated with the uncovered set are more precisely described than the set of tax vectors itself. As one might guess from Figure 2, the range of transfer rates associated with the tax vectors in the uncovered set is quite large. The transfer rates run from essentially zero to around $100 \%$ of GDP. Figure 3 plots a histogram that shows, in rough terms, the distribution of transfer rates associated with the tax vectors in the uncovered set. While extremely large transfers - rate in excess of, say, $50 \%$ of GDP - are relatively rare, there is still enormous variation in the transfer rates associated with the tax vectors in the uncovered set.

What are we to make of these results? One interpretation is that, without imposing much more structure on the political rules of the game, our model economy, calibrated roughly to stylized facts about the U.S. economy, is as likely to adopt redistributive factor income and consumption taxes that look like the U.S. system as it is to pick a set of taxes that looks much different. While the fact that taxes have efficiency consequences holds out hope that majority voting methods may allow a model economy to give sharp predictions about the sorts of redistributive tax schemes we are apt to observe, the range of potential outcomes is still so wide as to be useless. In this light,

\footnotetext{
${ }^{20} \mathrm{An}$ amendment procedure for voting amongst a finite set of alternatives fixes an agenda-say $\tau_{1}, \tau_{2}, \ldots, \tau_{M}-$ then pits $\tau_{M}$ against $\tau_{M-1}$, the winner versus $\tau_{M-2}$, the winner of that contest versus $\tau_{M-3}, \ldots$, and the winner of that contest versus $\tau_{1}$. Voting is sophisticated when voters take account of each others' optimal choices when making their voting decision, and anticipate the effect that votes cast at earlier stages in the agenda will have on the final outcome. Sophisticated voters may thus vote against their preferences at some stage in anticipation of the consequences of that stage's decision on later rounds of voting. See Banks [1] for a formal definition.

${ }^{21}$ The calculations use the first definition of covering presented above: $\tau_{j}$ covers $\tau_{i}$ if and only if $\tau_{j} P \tau_{i}$ and if $\tau_{h} P \tau_{j}$ then $\tau_{h} P \tau_{i}$. For the household preferences and grid of capital tax vectors used in these calculations, however, the majority preference relation does turn out to be complete, so the various definitions discussed above are equivalent for this problem.
} 
the variety of real-world policies evidenced in Table 1 is, perhaps, not as puzzling as it at first seems to be.

\subsection{How many of the alternatives in Table 1 are uncovered?}

To pursue this interpretation a bit further, suppose we take the data in Table 1 as the set of alternatives available to our model economy. Which policies are plausible outcomes of majorityrule processes in the context of our model? With the data in Table 1 as the issue space, we may repeat the computations of the last section.

The Pareto set turns out to be the entire issue space - that is, none of the 20 tax schemes in Table 1 can be ruled out purely on efficiency grounds. Note in particular that restricting the set of alternatives to those in Table 1 brings Sweden and Denmark back into the Pareto set, contra the implication of Figure 1 and its larger set of alternatives.

What about the uncovered set? The uncovered set consists of the 10 alternatives listed in Table 3. The alternatives are ranked in descending order according to their dominance scores - that is, the number of pairwise contests each alternative wins. The uncovered set is not reducible. ${ }^{22}$

$\begin{array}{ll}\text { 1. } & \text { 'Australia' } \\ \text { 2. } & \text { 'Canada' } \\ \text { 3. } & \text { 'United Kingdom' } \\ \text { 4. } & \text { 'Switzerland' } \\ \text { 5. } & \text { 'Netherlands' } \\ \text { 6. } & \text { 'United States' } \\ \text { 7. } & \text { 'Japan' } \\ \text { 8. } & \text { 'Portugal' } \\ \text { 9. } & \text { 'Norway' } \\ \text { 10. } & \text { 'Austria' }\end{array}$

Table 3: The uncovered set when the issue space is given by the data in Table 1. Sorted in order of descending dominance scores.

The matrix given by Table 4 is the dominance matrix for the 10 alternatives in the uncovered set. If the $i$ th-row, $j$ th-column element is equal to 1 , that means that alternative $i$ beats alternative $j$ in a pairwise contest. A Condorcet winner, then, would correspond to a row $i$ in which all elements $j \neq i$ were equal to one. No Condorcet winner exists here. The 'United States' alternative - row 6-beats 'Switzerland', 'Netherlands', 'Norway' and 'Austria' in pairwise contests. The 'United States' is beaten by 'Australia', 'Canada', 'United Kingdom', 'Japan' and 'Portugal'. Note that both 'Australia' and 'United Kingdom' are, in turn, beaten by both 'Norway' and 'Austria'.

\footnotetext{
${ }^{22}$ The definition of reducibility is given in Banks [1], who also gives criteria for verifying reducibility using the structure of the dominance matrix. If the uncovered set is reducible, it can be partitioned in such a way that all sophisticated voting outcomes lie in a particular subset of the uncovered set.
} 


\begin{tabular}{l|llllllllll}
\multicolumn{1}{l}{} & $\mathbf{1}$ & $\mathbf{2}$ & $\mathbf{3}$ & $\mathbf{4}$ & $\mathbf{5}$ & $\mathbf{6}$ & $\mathbf{7}$ & $\mathbf{8}$ & $\mathbf{9}$ & $\mathbf{1 0}$ \\
\cline { 2 - 9 } $\mathbf{1}$ & 0 & 1 & 0 & 1 & 1 & 1 & 1 & 1 & 0 & 0 \\
$\mathbf{2}$ & 0 & 0 & 0 & 1 & 0 & 1 & 1 & 1 & 1 & 1 \\
$\mathbf{3}$ & 1 & 1 & 0 & 1 & 0 & 1 & 1 & 1 & 0 & 0 \\
$\mathbf{4}$ & 0 & 0 & 0 & 0 & 1 & 0 & 1 & 1 & 1 & 1 \\
$\mathbf{5}$ & 0 & 1 & 1 & 0 & 0 & 0 & 0 & 1 & 1 & 1 \\
$\mathbf{6}$ & 0 & 0 & 0 & 1 & 1 & 0 & 0 & 0 & 1 & 1 \\
$\mathbf{7}$ & 0 & 0 & 0 & 0 & 1 & 1 & 0 & 0 & 1 & 1 \\
$\mathbf{8}$ & 0 & 0 & 0 & 0 & 0 & 1 & 1 & 0 & 1 & 1 \\
$\mathbf{9}$ & 1 & 0 & 1 & 0 & 0 & 0 & 0 & 0 & 0 & 1 \\
$\mathbf{1 0}$ & 1 & 0 & 1 & 0 & 0 & 0 & 0 & 0 & 0 & 0
\end{tabular}

Table 4: The dominance matrix for the alternatives in the uncovered set shown in Table 3.

The last point suggests that the majority preference relation is cyclic. In fact, one can construct a Condorcet cycle encompassing all 10 alternatives, a feature we should expect given the results of McKelvey [17] and the fact that there is no Condorcet winner. ${ }^{23}$ One such cycle is given in Table 5 ; there are perhaps others as well.

$\begin{array}{ll}\text { 'Australia' } & \text { defeats } \\ \text { 'Canada' } & \text { which defeats } \\ \text { 'Switzerland' } & \text { which defeats } \\ \text { 'Japan' } & \text { which defeats } \\ \text { 'Netherlands' } & \text { which defeats } \\ \text { 'United Kingdom' } & \text { which defeats } \\ \text { 'Portugal' } & \text { which defeats } \\ \text { 'United States' } & \text { which defeats } \\ \text { 'Norway' } & \text { which defeats } \\ \text { 'Austria' } & \text { which defeats } \\ \text { 'Australia'. } & \end{array}$

Table 5: A Condorcet cycle involving all 10 alternatives in the uncovered set.

These calculations provide perhaps the starkest depiction of the inconclusiveness of majorityvoting politics applied to the problem of redistributive taxation in this model economy. We have a simple growth model, calibrated to capture certain stylized features of long-run U.S. data, populated by households which are heterogeneous in wealth and labor productivity. The model captures the distortionary effects of taxation, and does so to a greater degree than the more commonly employed neoclassical growth model. The number of household types in the economy is small, though no type is large enough to be decisive. Inequality in the distributions of wealth and earnings ability are calibrated roughly to data on U.S. wealth inequality and wage inequality.

\footnotetext{
${ }^{23}$ McKelvey [17] showed in a very general framework that if the majority preference relation is at all intransitive then it will be completely intransitive, in the sense that virtually all alternatives can be put into a single cycle.
} 
The electorate in this section is faced with a simple choice among 20 alternative tax vectors, which reflect the wide variation in tax rates on consumption, labor income and capital income that we see in OECD data. None of the 20 alternatives can be ruled out as Pareto-dominated and only 10 can be eliminated as covered. The 10 alternatives in the uncovered set encompass a wide variety tax policies. No Condorcet winner exists, and the majority preference relation, on the uncovered set, is completely cyclic.

\section{Conclusions}

This paper asks, in the context of a simple growth model with heterogeneous households, what, if anything, the tools of majority voting can say about the redistributive taxation of capital income, labor income and consumption. The model is a two-sector $A K$ model, chosen in part because it highlights the distortionary effects of factor income taxes. Intuitively, the greater the distortionary effects of taxation, the more likely it is that majoritarian methods will yield a determinant prediction for redistributive taxes.

Households in the model differ in their initial wealth-holdings and in the productivity of their labor effort. Inequality in these characteristics is calibrated to match stylized facts on the U.S. distributions of wealth and wages. The most numerous household type in the calibrated model has a population share of $47 \%$, so no single type constitutes a majority of the electorate. The political decision is made at date zero, under full commitment, on constant paths of taxes. Taxes are used to finance a redistributive transfer and an exogenous level of government purchases. I focus on balanced growth equilibria in a version of the model calibrated roughly to U.S. data.

The main finding of the paper is the inconclusiveness of majority voting methods for deriving empirically substantive restrictions on equilibrium tax rates. Under probabilistic voting, the equilibrium tax vectors in the calibrated model prove to be extremely sensitive to assumptions on the random, non-policy elements in household preferences. In particular, depending on whether those elements enter household preferences additively or multiplicatively, the resulting equilibrium tax vectors are nearly orthogonal. While one equilibrium supports significant transfers, the other involves taxes that simply finance exogenous government consumption.

From probabilistic voting, I turn to other majority-voting solution concepts. I first look at the calibrated model's Pareto set - the set of tax vectors which cannot be unanimously defeated under majority voting. Given the sharp distortionary effects of taxes in the model - in particular capital income taxes, given the $A K$ structure - it's reasonable to hope to efficiency considerations alone may significantly narrow the range of possible political outcomes, and in fact the Pareto set is quite small relative to the entire issue space. However, comparing the Pareto set with average tax rates on consumption and factor income for a set of 20 OECD countries, I find that the Pareto set is nonetheless large relative to the wide variation in tax policies that we observe in the data. A similar conclusion holds for the calibrated model's uncovered set. Given the discrete grid 
of tax vectors on which I solve for the Pareto set and uncovered set, I find that no Condorcet winner exists. If we think in terms of two-party electoral competition, a Condorcet winner would constitute a dominant strategy for either candidate, while the uncovered set would constitute the set of strategies which are not dominated. Neither of these criteria proves to have any empirical bite.

One interpretation of these results is that, absent more structure on the political process, our model economy, calibrated to match features of the U.S. economy, cannot decide whether it wants a tax system like that of the U.S. or that of a European welfare state. As confirmation of this interpretation, I consider the model's predictions when the issue space consists of the tax vectors for the 20 countries in the OECD data. In that case, I find that all 20 tax vectors are in the Pareto set, 10 tax vectors are in the uncovered set, and no Condorcet winner exists. The 10 tax vectors in the uncovered set run the gamut from the U.S. data to countries like Austria and Norway. Majority preferences over those 10 alternatives are cyclic - one can construct a Condorcet cycle involving all 10 alternatives.

The inconclusiveness of majority-voting methods in this context-in contrast to the sharp results found in other papers in the literature on the endogenous determination of taxation and redistribution - stems from the fact that the issue space is multi-dimensional and, at the same time, no single voter type constitutes a majority of the electorate. It may be possible to deal with the dimensionality problem by imposing a sequential structure on voting, with one issue being decided at a time. But to do so in a way that is not simply ad hoc, one would, I think, need to specify procedures that were consistent with real-world political processes (or prove an irrelevance result). In order to see what we might conclude more generally, I've tried in this paper to avoid specifying such processes, except in the broadest terms.

One might also try to take seriously the probabilistic voting framework, and deal with the fragility of those results by justifying, empirically, a particular specification for the form and distribution of the random, non-policy elements in households' preferences. But here again, one has to get into the nitty gritty of real-world politics.

Finally, the whole set of problems can be dispensed with simply by modeling the population in such a way that, for each political decision taken, there is a household type that constitutes a majority of the electorate. Whether this is a reasonable assumption is open to argument. Less open to argument is whether it is an innocuous assumption, and the results in this paper seem to suggest that it is not.

\section{References}

[1] Banks, J. (1985): "Sophisticated Voting Outcomes and Agenda Control," Social Choice and Welfare, 1, pp. 295-306.

[2] Bianco, W., I. Jeliazkov and I. Sened (2004): "The Uncovered Set and the Limits of 
Legislative Action," Political Analysis, 12, pp. 256-276.

[3] Budria Rodriguez, S., J. Diaz-Gimenez, V. Quadrini and J.-V. Rios-Rull (2002): "Updated Facts on the U.S. Distributions of Earnings, Income and Wealth," Federal Reserve Bank of Minneapolis Quarterly Review, 26(3), pp. 2-35.

[4] Carey, D., and J. Rabesona (2002): "Tax Ratios on Labour and Capital Income and on Consumption," OECD Economic Studies: No. 35, 2002(2), pp. 129-174.

[5] Coughlin, P. (1992): Probabilistic Voting Theory. Cambridge, UK: Cambridge University Press.

[6] Davis, O., M. DeGroot and M. Hinich (1972): "Social Preference Orderings and Majority Rule," Econometrica, 40, pp. 147-157.

[7] DeDonder, P. (2000): "Majority Voting Solution Concepts and Redistributive Taxation," Social Choice and Welfare, 17, pp. 601-627.

[8] Jones, C. (1995): "Time Series Tests of Endogenous Growth Models," Quarterly Journal of Economics, 110, pp. 495-525.

[9] Hassler, J., J. Rodriguez Mora, K. Storesletten and F. Zilibotti (2003): "The Survival of the Welfare State," American Economic Review, 93, pp. 87-112.

[10] Hassler, J., P. Krusell, K. Storesletten and F. Zilibotti (2005): "The Dynamics of Government," Journal of Monetary Economics, 52, pp. 1331-1358.

[11] Katz, L., AND D. Autor (1999): "Changes in the Wage Structure and Earnings Inequality," in O. Ashenfelter and D. Card, eds., Handbook of Labor Economics Volume 3. Amsterdam: North-Holland Publishers.

[12] Krusell, P., V. Quadrini and J.-V. Rios-Rull (1996): "Are Consumption Taxes Really Better than Income Taxes?" Journal of Monetary Economics, 37, pp. 475-503.

[13] Krusell, P., and J.-V. Rios-Rull (1999): "On the Size of U.S. Government: Political Economy in the Neoclassical Growth Model," American Economic Review, 89, pp. 1156-1181.

[14] Lindbeck, A., And J. Weibull (1987): "Balanced-budget Redistribution as the Outcome of Political Competition," Public Choice, 52, pp. 273-297.

[15] Lindert, P. (2004): Growing public: Social Spending and Economic Growth since the Eighteenth Century, vols. 1 \& 2. Cambridge, UK: Cambridge University Press.

[16] McGrattan, E. (1998): "A Defense of AK Growth Models," Federal Reserve Bank of Minneapolis Quarterly Review, 22(4), pp. 13-27.

[17] McKelvey, R. (1979): "General Conditions for Global Intransitivities in Formal Voting Models" Econometrica, 47, pp. 1085-1112.

[18] Meltzer, A., and S. Richard (1981): "A Rational Theory of the Size of Government" Journal of Political Economy, 89, pp. 914-927.

[19] Mendoza, E., A. Razin and L. Tesar (1994): "Effective Tax Rates in Macroeconomics: Cross-country Estimates of Tax Rates on Factor Income and Consumption," Journal of Mon- 
etary Economics, 34, pp. 297-323.

[20] Miller, N. (1980): "A New Solution Set for Tournaments and Majority Voting: Further Graph-Theoretical Approaches to the Theory of Voting," American Journal of Political Science, 24, pp. 68-96.

[21] Ordeshook, P. (1986): Game Theory and Political Theory: An Introduction Cambridge, UK: Cambridge University Press.

[22] Plott, C. (1967): "A Notion of Equilibrium and Its Possibility under Majority Rule," American Economic Review, 57, pp. 787-806.

[23] Rebelo, S. (1991): "Long-run Policy Analysis and Long-run Growth," Journal of Political Economy, 99, pp. 500-521.

[24] Yang C., (1995): "Endogenous Tariff Formation under Representative Democracy: A Probabilistic Voting Model," American Economic Review, 85, pp. 956-963.

\section{A Appendix}

\section{A.1 The household's intertemporal problem}

Let $M\left(k_{t}, k_{t+1}, \ldots\right)$ denote the household's maximized value of $c l^{\psi}$, given $k_{t}, k_{t+1}$ and everything else (prices, government policy variables, and the household's value of $e$, represented by the '...'), in the case where the $l \leq 1$ constraint is not binding. In terms of the equations in section 2.2 , we substitute (11) and (12) into (9) to get

$$
\begin{aligned}
M\left(k_{t}, k_{t+1}, \ldots\right)= & \left(\frac{1}{(1+\psi)\left(1+\tau_{c}\right)}\right)\left(\frac{\psi}{(1+\psi)\left(1-\tau_{n}\right) w_{t} e}\right)^{\psi} \times \\
& {\left[\left(\left(1-\tau_{k}\right) r_{t}+(1-\delta) q_{t}\right) k_{t}+\left(1-\tau_{n}\right) w_{t} e+T_{t}-q_{t} k_{t+1}\right]^{1+\psi} . }
\end{aligned}
$$

Let $\hat{M}\left(k_{t}, k_{t+1}, \ldots\right)$ be defined similarly, for the case where $l=1$, i.e.,

$$
\hat{M}\left(k_{t}, k_{t+1}, \ldots\right)=\frac{1}{1+\tau_{c}}\left[\left(\left(1-\tau_{k}\right) r_{t}+(1-\delta) q_{t}\right) k_{t}+T_{t}-q_{t} k_{t+1}\right] .
$$

As discussed in the text, along a balanced growth path, the $l \leq 1$ constraint for a given household will either bind in every period or be slack in every period-i.e., the right-hand side of (13) will be positive for some $(e, s)$ types and negative for others, but will always consist of constants along a balanced path. Conversely, while it may be feasible for a household to choose a path of capital that makes the constraint binding in one period and slack in another, such paths necessarily involve non-constant growth rates for the household's capital stock, hence are inconsistent with balanced growth. ${ }^{24}$ To characterize balanced growth equilibria, then, it suffices to consider the household's

\footnotetext{
${ }^{24}$ To see this, one need simply consider the Euler equation that arises from perturbing $k_{t+1}$ in $\cdots+$ $\beta^{t} M\left(k_{t}, k_{t+1}, \ldots\right)+\beta^{t+1} \hat{M}\left(k_{t+1}, k_{t+2}, \ldots\right)+\cdots$.
} 
intertemporal problem when either $M\left(k_{t}, k_{t+1}, \ldots\right)$ is always relevant or $\hat{M}\left(k_{t}, k_{t+1}, \ldots\right)$ is always relevant.

The Euler equations for a constrained household take the form

$$
q_{t} \hat{M}\left(k_{t}, k_{t+1}, \ldots\right)^{-1 / \varepsilon}=\beta\left[\left(1-\tau_{k}\right) r_{t+1}+(1-\delta) q_{t+1}\right] \hat{M}\left(k_{t+1}, k_{t+2}, \ldots\right)^{-1 / \varepsilon}
$$

or (taking account of the definition of $\hat{M}$ and re-arranging slightly)

$$
\begin{aligned}
& {\left[\left(1-\tau_{k}\right) r_{t+1}+(1-\delta) q_{t+1}\right] k_{t+1}+T_{t+1}-q_{t+1} k_{t+2} } \\
= & \left(\frac{\beta\left[\left(1-\tau_{k}\right) r_{t+1}+(1-\delta) q_{t+1}\right]}{q_{t}}\right)^{\varepsilon}\left(\left[\left(1-\tau_{k}\right) r_{t}+(1-\delta) q_{t}\right] k_{t}+T_{t}-q_{t} k_{t+1}\right) .
\end{aligned}
$$

Note that if $q_{t+1} / q_{t}$ is constant and $r_{t+1} / q_{t+1}=A$,

$$
\left(\frac{\beta\left[\left(1-\tau_{k}\right) r_{t+1}+(1-\delta) q_{t+1}\right]}{q_{t}}\right)^{\varepsilon}=\left(\left(1+g_{q}\right)\left[\left(1-\tau_{k}\right) A+1-\delta\right]\right)^{\varepsilon} \equiv 1+\gamma .
$$

If $T_{t}$ grows at rate $\gamma$ the Euler equation (25) reduces to

$$
\begin{aligned}
& \left(1+g_{q}\right)\left[\left(1-\tau_{k}\right) A+1-\delta\right] q_{t+1} k_{t+1}-q_{t+2} k_{t+2} \\
= & (1+\gamma)\left(\left(1+g_{q}\right)\left[\left(1-\tau_{k}\right) A+1-\delta\right] q_{t} k_{t}-q_{t+1} k_{t+1}\right)
\end{aligned}
$$

which is satisfied if $q_{t} k_{t}$ grows at rate $\gamma$ as well. With $T_{t}$ and $q_{t} k_{t}$ growing at rate $\gamma$, the household's budget constraint implies that $c_{t}$ grows at rate $\gamma$ as well.

The Euler equations for an unconstrained household are somewhat more complicated than (25). Assuming, as above, that $q_{t+1} / q_{t}$ is constant, that $r_{t+1} / q_{t+1}=A$ and that $\gamma$ is as defined in (26), and after cancelling constants from both sides, we obtain

$$
\begin{aligned}
& w_{t+1}^{\phi}\left(\left[\left(1-\tau_{k}\right) A+1-\delta\right] q_{t+1} k_{t+1}+\left(1-\tau_{n}\right) w_{t+1} e+T_{t+1}-q_{t+1} k_{t+2}\right)^{1-\phi} \\
= & (1+\gamma) \times w_{t}^{\phi}\left(\left[\left(1-\tau_{k}\right) A+1-\delta\right] q_{t} k_{t}+\left(1-\tau_{n}\right) w_{t} e+T_{t}-q_{t} k_{t+1}\right)^{1-\phi}
\end{aligned}
$$

where $\phi \equiv \psi(\varepsilon-1)$. Suppose now that both $T_{t}$ and $w_{t}$ grow at rate $\gamma$. The last expression then reduces to (27), from which it follows that a path of capital such that $q_{t} k_{t}$ grows at rate $\gamma$ is a solution. Again, the household's budget constraint implies that $\gamma$ is the growth rate of consumption.

\section{A.2 Balanced growth equilibrium}

Given household budget constraints and the economy's resource constraints, a balanced growth equilibrium must have (a) $N$ and $\eta$ constant (since they are bounded between 0 and 1); (b) 
consumption - at the household level and in the aggregate, private and public - growing at a constant rate $g_{Z}$, which is shared by the wage rate, transfer payment and the value of capital; (c) individual and aggregate capital stocks growing at a constant rate $g_{K}$; (d) the relative price of capital and the rental rate growing at a common rate $g_{q}$. The values of $N$ and $\eta$, and the three growth rates, must be consistent with household and firm optimization and the economy's resource constraints.

The discussion of a typical household's intertemporal optimization problem in the last section showed that when the zero profit condition $q_{t} A=r_{t}$ held and $q_{t}$ grew at a constant rate $g_{q}$, there was a growth rate $\gamma$ that, if shared by $w_{t}$ and $T_{t}$, implied that households chose paths of capital such that $q_{t} k_{t}$ grew at rate $\gamma$ as well, and that household consumption grew at rate $\gamma$ also. That $\gamma$ will be the consumption growth rate $g_{Z}$ in balanced growth equilibrium.

Using equation (26), we have

$$
1+g_{Z}=\left(\left(1+g_{q}\right)\left[\left(1-\tau_{k}\right) A+1-\delta\right]\right)^{\varepsilon} .
$$

From the technology for producing $Z$, we know that $1+g_{Z}=\left(1+g_{K}\right)^{\alpha}$, and so if $q_{t} k_{t}$ is to grow at $g_{Z}$, it must be the case that $1+g_{q}=\left(1+g_{K}\right)^{\alpha-1}=\left(1+g_{Z}\right)^{1-\frac{1}{\alpha}}$. This pins down the equilibrium consumption growth rate as

$$
1+g_{Z}^{*}=\left[\left(1-\tau_{k}\right) A+1-\delta\right]^{\frac{\alpha \varepsilon}{\alpha+\varepsilon(1-\alpha)}} .
$$

Since $q_{t} A=r_{t}$, firms are indifferent about their choice of $\eta$, so we may set $\eta^{*}$ to be consistent with

$$
1+g_{Z}^{*}=\left(1+g_{K}\right)^{\alpha}=[A(1-\eta)+1-\delta]^{\alpha},
$$

using $K_{t+1} / K_{t}=A(1-\eta)+1-\delta$. This determines $\eta^{*}$.

To determine $N^{*}$, we turn to the decision rules governing household labor supply. Recall that a household which supplies a positive amount of effective labor hours supplies

$$
e n_{t}=\frac{1}{1+\psi} e-\frac{\psi}{1+\psi} \frac{\left(1-\tau_{k}\right) r_{t} k_{t}+T_{t}-q_{t}\left[k_{t+1}-(1-\delta) k_{t}\right]}{\left(1-\tau_{n}\right) w_{t}} .
$$

units of effective labor. Moreover, the households which supply a positive amount of hours are precisely those for which the right-hand side of the last equation is positive. Using $r_{t}=\alpha Z_{t} / \eta^{*} K_{t}$, $w_{t}=(1-\alpha) Z_{t} / N, q_{t}=r_{t} / A$, and the feature of a balanced growth equilibrium that $k_{t+1}=$ $\left(1+g_{K}\right) k_{t}=\left[A\left(1-\eta^{*}\right)+1-\delta\right] k_{t}$, we can derive

$$
\frac{\left(1-\tau_{k}\right) r_{t} k_{t}-q_{t}\left[k_{t+1}-(1-\delta) k_{t}\right]}{\left(1-\tau_{n}\right) w_{t}}=\frac{\eta^{*}-\tau_{k}}{(1-\alpha)\left(1-\tau_{n}\right)} \frac{\alpha}{\eta^{*}} \frac{k_{t}}{K_{t}} N
$$


Also, using $w_{t} N+r_{t} K_{t}=\left(1-\alpha+\alpha / \eta^{*}\right) Z_{t}$, the government's budget constraint, and $G_{t}=\lambda Z_{t}$, we get

$$
\frac{T_{t}}{\left(1-\tau_{n}\right) w_{t}}=\frac{\tau_{k} \alpha / \eta^{*}+\tau_{n}(1-\alpha)+\tau_{c}(1-\lambda)-\lambda}{\left(1-\tau_{n}\right)(1-\alpha)} N .
$$

Substituting (29) and (30) into (28) - and taking account of the fact that in a balanced growth equilibrium, $k_{t} / K_{t}=k_{0} / K_{0}=s$-we obtain the expression which was claimed in section 2.4 to be the labor supply of an unconstrained household along a balanced growth path, for a given value of aggregate effective labor supply $N$ :

$$
\frac{1}{1+\psi} e-\frac{\psi}{1+\psi}\left\{\frac{\eta^{*}-\tau_{k}}{(1-\alpha)\left(1-\tau_{n}\right)} \frac{\alpha}{\eta^{*}} s+\frac{\tau_{k} \alpha / \eta^{*}+\tau_{n}(1-\alpha)+\tau_{c}(1-\lambda)-\lambda}{\left(1-\tau_{n}\right)(1-\alpha)}\right\} N,
$$

As discussed in the text, denoting the last expression by $\Phi(e, s ; N, \tau)$, the equilibrium value of aggregate effective labor effort, $N^{*}$, is defined implicitly by

$$
N=\sum_{(e, s) \in \mathfrak{T}} p(e, s) \max \{\Phi(e, s ; N, \tau), 0\}
$$

At any date $t$ along the balanced growth path, $K_{t}^{*}=\left[A\left(1-\eta^{*}\right)+1-\delta\right]^{t} K_{0}, Z_{t}^{*}=\left(\eta^{*} K_{t}^{*}\right)^{\alpha}\left(N^{*}\right)^{1-\alpha}$, $w_{t}^{*}=(1-\alpha) Z_{t}^{*} / N^{*}, r_{t}^{*}=\alpha Z_{t}^{*} /\left(\eta^{*} K_{t}^{*}\right)$, and $q_{t}^{*}=r_{t}^{*} / A$. Household choices obey $c_{t}(e, s)=$ $\left(1+g_{Z}\right)^{t} c_{0}(e, s), k_{t}(e, s)=\left(1+g_{K}\right)^{t} s$ and $l_{t}(e, s)=l_{0}(e, s)$ for all $t$. An unconstrained household has

$$
c_{0}(e, s)=\frac{1}{(1+\psi)\left(1+\tau_{c}\right)}\left\{\left(\eta^{*}-\tau_{k}\right) r_{0}^{*} s+\left(1-\tau_{n}\right) w_{0}^{*} e+T_{0}\right\}
$$

and

$$
l_{0}(e, s)=\frac{\psi}{(1+\psi)\left(1-\tau_{n}\right) w_{0}^{*} e}\left\{\left(\eta^{*}-\tau_{k}\right) r_{0}^{*} s+\left(1-\tau_{n}\right) w_{0}^{*} e+T_{0}\right\},
$$

while a constrained household has

$$
c_{0}(e, s)=\frac{1}{1+\tau_{c}}\left\{\left(\eta^{*}-\tau_{k}\right) r_{0}^{*} s+T_{0}\right\}
$$

and

$$
l_{0}(e, s)=1 \text {. }
$$

We can substitute $T_{0}$ out of these expressions, noting that in equilibrium

$$
T_{0}=\left[\tau_{k}\left(\alpha / \eta^{*}\right)+\tau_{n}(1-\alpha)+\tau_{c}(1-\lambda)-\lambda\right] Z_{0}^{*}
$$

These are the expressions used to construct $c_{0}(e, s) l_{0}(e, s)^{\psi}$ in the derivation of households' preferences over policies in section 4.1. 


\section{A.3 Parameter restrictions to guarantee solutions to the household's problem}

As in many models of economic growth, the key parameter restrictions necessary to guarantee existence of solutions to the households' intertemporal problems take the form of a Brock-Galetype condition that relates the growth rate of consumption, the discount factor and the curvature of the utility function. The condition in our case is

$$
\beta\left(1+g_{Z}\right)^{1-\frac{1}{\varepsilon}}<1
$$

With $1+g_{Z}=[A(1-\eta)+1-\delta]^{\alpha}$, this condition becomes

$$
\beta[A(1-\eta)+1-\delta]^{\alpha\left(1-\frac{1}{\varepsilon}\right)}<1 .
$$

We want to restrict the parameters $\beta, A, \delta, \alpha$ and $\varepsilon$ such that this inequality can be attained for $\eta$ between zero and one. In our calibrated model $\varepsilon<1$, so $[A(1-\eta)+1-\delta]^{\alpha\left(1-\frac{1}{\varepsilon}\right)}$ is maximized when $\eta=1$. If, therefore,

$$
\beta(1-\delta)^{\alpha\left(1-\frac{1}{\varepsilon}\right)}<1,
$$

then (31) will be satisfied at all values of $\eta \in[0,1]$. For our calibrated model, $\beta(1-\delta)^{\alpha\left(1-\frac{1}{\varepsilon}\right)} \cong$ 0.86 , so the condition is satisfied. Note, too, that when (31) holds, households' transversality conditions are automatically satisfied in a balanced growth equilibrium.

\section{A.4 Calibrating the model}

In the two-sector $A K$ model used in this paper, key ratios like labor's share of national income or consumption's share of output depend on the economy's balanced growth rate, which in turn depends on the rate of capital income taxation. Also, as in the neoclassical growth model, the balanced growth allocation of hours to work and leisure depends on both the labor income tax rate and the consumption tax rate. Therefore, I calibrate the model to generate a particular balanced growth path-meeting the targets in Table 2 - for a specific set of taxes $\bar{\tau}=\left(\bar{\tau}_{c}, \bar{\tau}_{n}, \bar{\tau}_{k}\right)$. In particular I take $\bar{\tau}$ to be the vector of tax rates for the U.S. as given in Table 1. For simplicity, I will refer to the balanced growth path associated with this vector of taxes as the 'benchmark equilibrium'.

Let $s_{c}$ and $s_{g}$ denote the output shares of private and government consumption, and let $s_{n}$ denote labor's share of national income. With $G_{t}=\lambda Z_{t}$, government's share of output obeys

$$
s_{g}=\frac{G}{Y}=\frac{\lambda Z}{Y}=\lambda\left(\frac{C+G}{Y}\right)=\lambda\left(s_{c}+s_{g}\right),
$$


so that

$$
\lambda=\frac{s_{g}}{s_{g}+s_{c}} .
$$

Thus, target values for $s_{c}$ and $s_{g}$ imply a value for $\lambda$.

From the expression for national income, (4), and using the first-order condition $w_{t}=(1-\alpha) Z_{t} / N_{t}$, labor's share of national income can be written as

$$
s_{n}=\frac{1-\alpha}{1-\alpha+\frac{\alpha}{\eta}} .
$$

Using $C_{t}+G_{t}=Z_{t}$, the consumption goods' share of output can be written as

$$
s_{c}+s_{g}=\frac{1}{1-\alpha+\frac{\alpha}{\eta}}
$$

Note that both shares depend on $\eta$ which describes the allocation of capital between the consumptionproducing and capital-producing sectors.

Given target values for $s_{n}, s_{c}$ and $s_{g},(32)$ and (33) constitute two equations in the two unknowns $\alpha$ and $\eta$. Their solution is

$$
\alpha=1-\frac{s_{n}}{s_{c}+s_{g}}
$$

and

$$
\eta=\frac{s_{c}+s_{g}-s_{n}}{1-s_{n}}
$$

The solution for $\alpha$ is our calibration of that parameter, given targets values for the $s_{i}$ 's. $\eta$, of course, is an endogenous variable, so the solution for $\eta$ is a value that must hold in the benchmark equilibrium if that equilibrium is to have consumption and labor income shares that match the target values. Call the particular value of $\eta$ given by the last equation $\bar{\eta}$. The other parameters of the model must be such that $\eta=\bar{\eta}$ holds in the benchmark equilibrium.

Assuming that $\eta=\bar{\eta}$, the growth rate of capital in the benchmark equilibrium is

$$
1+g_{K} \equiv \frac{K_{t+1}}{K_{t}}=A(1-\bar{\eta})+1-\delta
$$

As described in section 3 , the depreciation rate $\delta$ is set to be 0.10 , without regard to the benchmark equilibrium. Since the consumption growth rate obeys $1+g_{Z}=\left(1+g_{K}\right)^{\alpha}$, we can derive the following expression for $A$ :

$$
A=\frac{\left(1+g_{Z}\right)^{1 / \alpha}-(1-\delta)}{1-\bar{\eta}}
$$

Given $\alpha, \delta$ and $\bar{\eta}$, this value of $A$ implies that consumption growth in the benchmark equilibrium 
will match the target rate $g_{Z}$.

The last step for this group of parameters is to give a condition on $\beta$, the discount factor, so that $\bar{\eta}$ is in fact chosen in the benchmark equilibrium. We may write a typical household's Euler equation in the benchmark equilibrium as

$$
\left(1+g_{Z}\right)^{1 / \varepsilon}=\beta\left(1+g_{q}\right)\left[\left(1-\bar{\tau}_{k}\right) A+1-\delta\right] .
$$

The left-hand side is consumption growth, with exponent equal to the inverse of the elasticity of intertemporal substitution. The right-hand side is $\beta$ times the return to investment in capital. As shown in section $2.1,1+g_{Z}=\left(1+g_{K}\right)^{\alpha}$ and $1+g_{q}=\left(1+g_{K}\right)^{\alpha-1}$, so we may write

$$
[A(1-\bar{\eta})+1-\delta]^{\alpha / \varepsilon+1-\alpha}=\beta\left[\left(1-\bar{\tau}_{k}\right) A+1-\delta\right] .
$$

Since $\varepsilon$, like $\delta$, has been set exogenously, all the parameters in the equation but $\beta$ are fixed. Fixing the parameter $\beta$ equal to the value that satisfies this equation guarantees $\bar{\eta}$ is chosen in the benchmark equilibrium.

The remaining parameter to be set is $\psi$, which affects the household's allocation of time between leisure and working. As described in section 3, I calibrate $\psi$ as if all households were aggregated into a representative household - that is, as if there were a household with consumption equal to aggregate consumption and hours worked equal to aggregate hours worked. The intratemporal first-order condition for such a household is

$$
\psi \frac{C_{t}}{1-N}=\frac{1-\bar{\tau}_{n}}{1+\bar{\tau}_{c}} w_{t}
$$

Using $C_{t}=(1-\lambda) Z_{t}$ and $w_{t}=(1-\alpha) Z_{t} / N$, we have

$$
\psi=\left(\frac{1-\bar{\tau}_{n}}{1+\bar{\tau}_{c}}\right)\left(\frac{1-\alpha}{1-\lambda}\right)\left(\frac{1-N}{N}\right)
$$

Given $\alpha, \lambda, \bar{\tau}_{n}$ and $\bar{\tau}_{c}$, and setting $N$ equal to its target value of 0.30 , the last expression gives our calibration of $\psi$. 
Figure 1

The model's Pareto set (blue circles), together with the data from Table 1 (red diamonds). Tax rates are in percent.

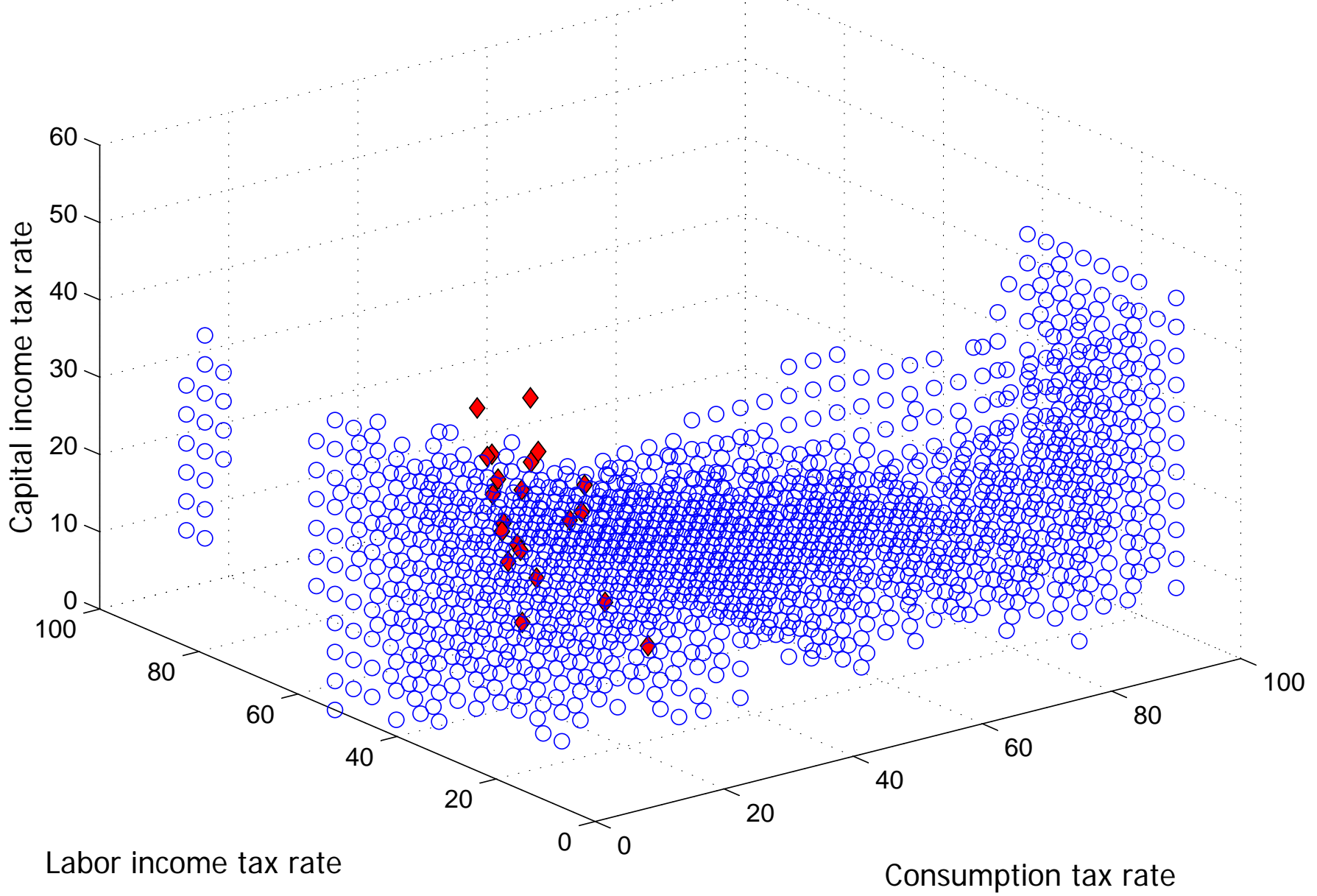


Figure 2

The model's uncovered set (blue circles), together with the data from Table 1 (red diamonds). Tax rates are in percent.

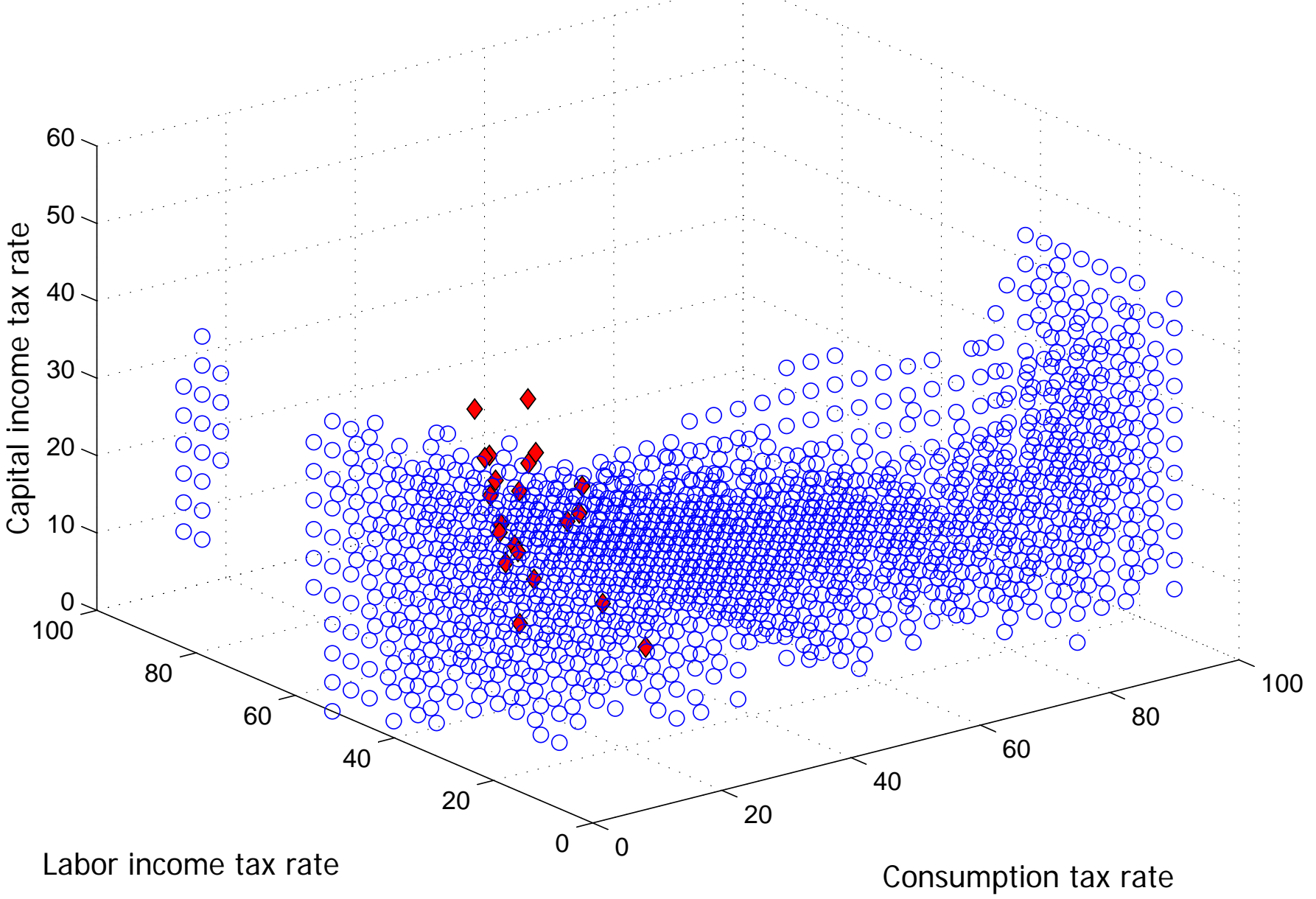


Figure 3

Histogram showing the frequency of transfer rates associated with the tax vectors in the uncovered set of Figure 2

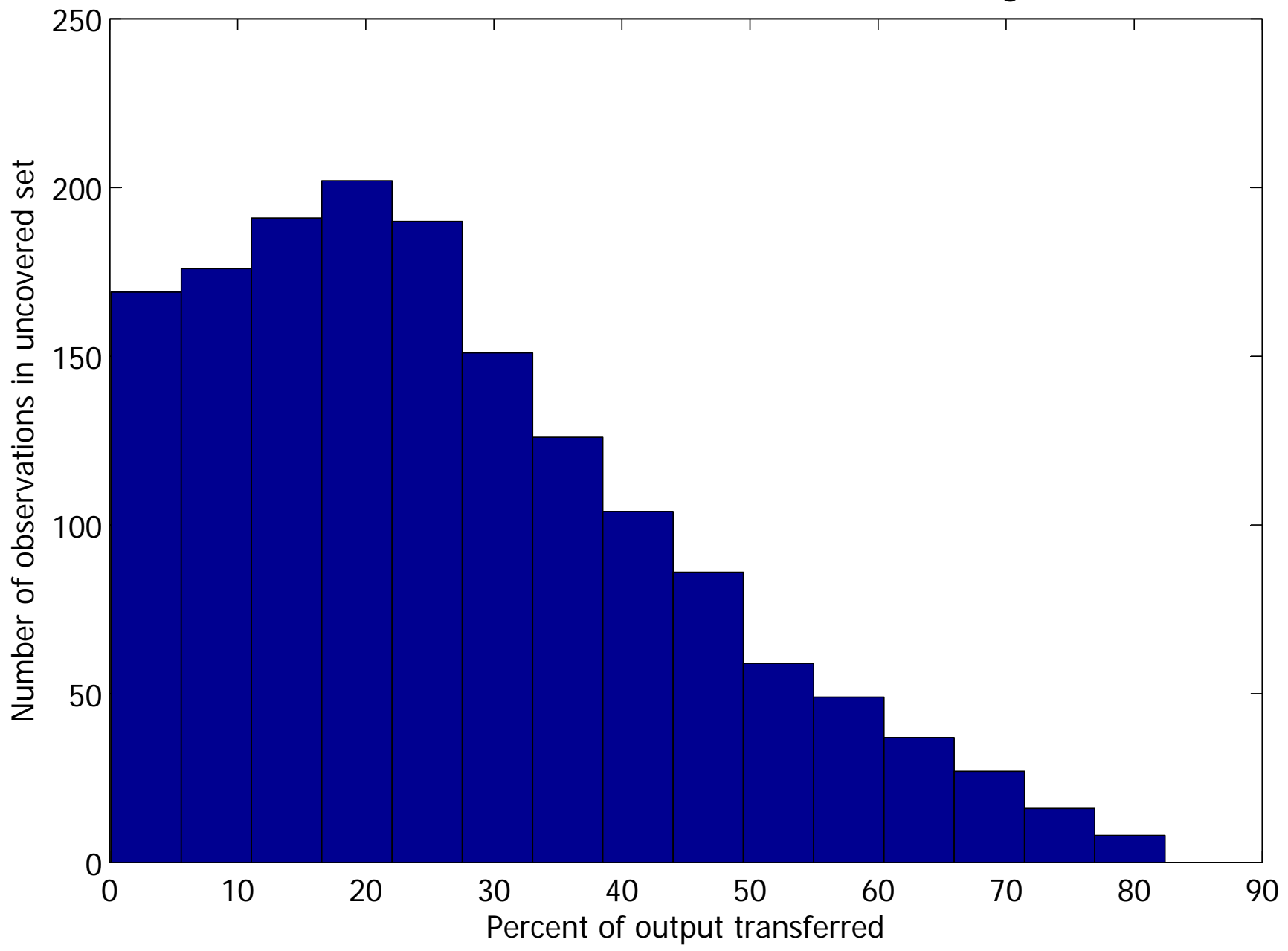

